\title{
Recovery of Bioenergetics Parameters from Information on Growth: Over- view of an Approach Based on Statistical Analysis of Tagging and Size-At- Age Data
}

\author{
Carl Walters ${ }^{1}$ and Timothy Essington*,2 \\ ${ }^{I}$ Fisheries Centre, University of British Columbia, Vancouver, B.C. V6T1Z4, Canada \\ ${ }^{2}$ School of Aquatic and Fishery Sciences, University of Washington, Box 355020, Seattle, WA 98195-5020, USA
}

\begin{abstract}
Parameters for size allometry in feeding and metabolic rates, along with Q10 parameters for responses of these rates to seasonal temperature change, can in principle be estimated from field data on growth, particularly seasonal tagging studies. However, it is still typically necessary to complement or constrain the field estimates with information from laboratory studies, particularly on power parameters for size allometry in metabolism, Q10 for metabolism, and responses of feeding rate at high temperatures. Ontogenetic habitat shifts can cause apparent changes in the size power parameters that are in fact due to temperature differences between the habitats. Seasonal changes in body condition (due to feeding, metabolism, and reproduction) can be represented using simple models for allocation of food intake to skeletal growth, though parameter estimation for such models is grossly unreliable when only seasonal changes in length growth rates have been measured.
\end{abstract}

Keywords: Bioenergetics models, food consumption rates, temperature, condition factor.

\section{INTRODUCTION}

Estimates of trophic interaction effects are of growing importance in development of aquatic ecosystem policies. Such effects are typically estimated by combining abundance estimates with diet composition data and estimates of food consumption rates from bioenergetics models. The bioenergetics models have in turn relied substantially upon parameter estimates from laboratory studies. While case studies like Hayes et al. 2000 [1] indicate that extrapolation from laboratory to field can be very successful, there is a need for methods to at least cross-validate such parameter estimates using direct field observations of growth rate and metabolism patterns [2].

It has long been recognized that size-dependent growth rates in the field contain information about both food consumption and metabolism. The VonBertalanffy "growth" parameter $\mathrm{K}$ in fact represents variation in metabolic costs with body size and is close to $1 / 3$ of the annual standard metabolic rate per unit body weight [3-5], under the assumption that standard metabolism (plus loss of energy to reproductive products) is simply proportional to body weight (rather than some lower power of weight).

This paper discusses the use of various generalizations of the VonBertalanffy model for estimation of feeding and metabolism parameters from size-at-age data and growth increment data from tagging. We first review general bioenergetics models that have less restrictive assumptions than the

*Address correspondence to this author at the School of Aquatic and Fishery Sciences, University of Washington, Box 355020, Seattle, WA 981955020, USA: Tel: 604-822-6320; Fax: 604-822-8934;

E-mail: c.walters@fisheries.ubc.ca
VonBertalanffy about size dependence in anabolism and catabolism, and develop a robust statistical method for estimating the parameters of such models from tagging data. Then we examine the possibility of recovering parameters for seasonal, temperature driven variation in food consumption and metabolism rates from seasonal tagging and growth data, in particular for cases where seasonal changes in rates along with seasonal investment in reproductive patterns cause changes in body condition. Recovery of information about responses to temperature may be particularly useful in development of models for predicting impacts on fish performance of climate change.

We illustrate the parameter estimation methods with case studies on a range of species. The case studies are described in more detail in the other papers that make up this Supplement. Here we present and review some data and graphics from those case studies for readers who seek only overview information, but strongly we strongly encourage readers to examine the case studies in more detail.

Symbols used in the model derivations are summarized in Table 1. Parameter estimates obtained for case studies used to test estimation procedures and for comparison to results from laboratory studies are summarized in Table 2 and Table 3.

\section{DERIVATION OF A BIOENERGETICS MODEL FOR LENGTH DYNAMICS}

As in Essington et al. [5], we begin with a general bioenergetics model for growth in body weight $\mathrm{W}$, then convert this to a model for growth in length by using a length-weight relationship. We assume first that growth in body weight can be predicted from [6]: 
Table 1. Definitions of Symbols for Equations

\begin{tabular}{|c|c|c|}
\hline Symbol & Definition & Units \\
\hline $\mathrm{H}$ & Net food consumption rate per $\mathrm{W}^{-\mathrm{d}}$ & $\mathrm{g} \mathrm{g}^{-\mathrm{d}} \mathrm{yr}^{-1}$ \\
\hline $\mathrm{d}$ & Food consumption power parameter & -- \\
\hline $\mathrm{m}$ & Standard metabolic rate per $\mathrm{W}^{-\mathrm{n}}$ & $\mathrm{g} \mathrm{g}^{-1} \mathrm{yr}^{-1}$ \\
\hline $\mathrm{C}_{\max }$ & Maximum food consumption rate per $\mathrm{W}^{-\mathrm{d}}$ & g g-d yr-1 \\
\hline $\mathrm{p}$ & Proportion of maximum ration achieved & -- \\
\hline $\mathrm{e}$ & Efficiency of food conversion (assimilation x 1-SDA) & -- \\
\hline $\mathrm{R}$ & Feeding rate (ration) & $\mathrm{g} \mathrm{yr}^{-1}$ \\
\hline $\mathrm{b}$ & power coefficient of length-weight relationship & -- \\
\hline$\alpha$ & Anabolic coefficient for length growth & $\mathrm{cm} \mathrm{cm}^{-8} \mathrm{yr}^{-1}$ \\
\hline$\delta$ & Power coefficient for anabolic term in length growth & -- \\
\hline$\kappa$ & Metabolic coefficient for length growth & $\mathrm{cm} \mathrm{cm}^{-\eta} \mathrm{yr}^{-1}$ \\
\hline$\eta$ & Power coefficient for metabolism in length growth & -- \\
\hline $\mathrm{L}_{\infty}$ & Maximum body length & $\mathrm{cm}$ \\
\hline $\mathrm{L}_{1}$ & Measured body length at tagging & $\mathrm{cm}$ \\
\hline $\mathrm{L}_{1}$ & Measured body length at recapture & $\mathrm{cm}$ \\
\hline $\mathrm{D}$ & Deviation between predicted and observed $\mathrm{L}_{2}$ & $\mathrm{~cm}$ \\
\hline $\mathrm{T}$ & Water temperature & ${ }^{\circ} \mathrm{C}$ \\
\hline $\mathrm{Q}_{\mathrm{c}}$ & Proportional increase in feeding rate per $10^{\circ}$ temperature increase & -- \\
\hline $\mathrm{Q}_{\mathrm{m}}$ & Proportional increase in metabolism per $10^{\circ}$ temperature increase & -- \\
\hline $\mathrm{T}_{\mathrm{a}}$ & Mean annual water temperature & ${ }^{\circ} \mathrm{C}$ \\
\hline g & Steepness parameter for decrease in feeding at high temperatures & ${ }^{\circ} \mathrm{C}^{-1}$ \\
\hline $\mathrm{T}_{\mathrm{m}}$ & Water temperature at which feeding drops by half & ${ }^{\circ} \mathrm{C}$ \\
\hline $\mathrm{W}_{\mathrm{s}}$ & Weight of body structural tissues & g \\
\hline $\mathrm{f}_{\mathrm{s}}$ & Proportion of intake or surplus intake allocated to growth of structural tissue & -- \\
\hline$f^{*}{ }_{s}$ & Normal structural tissue proportion of body weight & -- \\
\hline$\theta$ & Slope parameter for decreasing allocation to structural tissue as $\mathrm{W}_{\mathrm{s}} / \mathrm{W}$ varies around $\mathrm{f}_{\mathrm{s}}$ & -- \\
\hline $\mathrm{W}_{\infty}$ & Body weight at which allocation to skeletal growth declines to zero & g \\
\hline $\mathrm{R}_{\mathrm{i}}$ & Relative size of individual $i$ at all ages, as a multiple of population mean size & -- \\
\hline$\sigma^{2}{ }_{R}$ & Variance of $R_{i}$ among individuals (square of $C V$ of individual $L_{\infty}$ values) & $\mathrm{cm}^{2}$ \\
\hline
\end{tabular}


Table 2. Summary of Bioenergetics Parameter Estimates for the Case Examples Examined in this Study, Asterisks Denote Assumed Parameter Values for Situations Where we Were Unable to Obtain Reasonable Estimates by Fitting to Tag Recapture and/or Length at Age Data. Parameters Defined in Table 1. Note that the Temperature Inactivation Parameter $T_{m}$ was Set Large (1000) for all Cases, Since the Temperatures for the Systems Examined were all Low Relative to Tolerance Limits for the Species Involved. Rainbow Trout and Humpback Chub Estimates are for the Simple CR Model, Brown Trout and Pikeminnow for the SRSA Model

\begin{tabular}{|c|c|c|c|c|}
\hline Parameter & $\begin{array}{c}\text { Rainbow Trout } \\
\text { (Cabin Lake) }\end{array}$ & $\begin{array}{c}\text { Brown Trout } \\
\text { (Maruia River) }\end{array}$ & $\begin{array}{c}\text { Humpback Chub } \\
\text { (Colorado River) }\end{array}$ & $\begin{array}{c}\text { Pikeminnow } \\
\text { (Bonaparte Plateau) }\end{array}$ \\
\hline \hline $\mathrm{H}$ & 18.37 & 6.04 & 21.06 & 0.48 \\
\hline $\mathrm{m}$ & 0.46 & 0.36 & 0.61 & 0.24 \\
\hline $\mathrm{d}$ & 0.78 & 0.76 & 0.88 & $1.00^{*}$ \\
\hline $\mathrm{n}$ & 1.07 & $1.00^{*}$ & $2.0 *$ & $2.92 *$ \\
\hline $\mathrm{Q}_{\mathrm{m}}$ & 2.48 & $7.69 *$ & 4.59 & 9.71 \\
\hline $\mathrm{Q}_{\mathrm{c}}$ & 2.81 & $5.52^{*}$ & $\mathrm{na}$ & $0.02 *$ \\
\hline$\theta$ & $\mathrm{na}$ & 0.05 & $\mathrm{na}$ & $270.00^{*}$ \\
\hline $\mathrm{W}_{\infty}$ & $\mathrm{na}$ & 7424.90 & & 2 \\
\hline
\end{tabular}

Table 3. Parameter Estimates from the Complex SRSA Bioenergetics Model with Seasonal Reproduction and Allocation to Skeletal Growth, and the Complex Likelihood Function for Tagging Data from Seasonally Reproducing Species (eqs. 12-19, 22), for a Set of Case Examples with Widely Varying Sample Sizes and Life History Characteristics. Parameters as Defined in Table 1. ** Indicates Parameter Estimate at Constraint Boundary Largemouth bass (Micropterus salmoides) Populations are Florida West Coast River Populations that Use Estuarine Areas with Variable Salinity; Bass in the Homossassa River Feed Mainly on Smaller Prey Items than in the Chassowiska River [34]. Flathead Catfish (Pylodictis olivaris) Data from Introduced Populations in North Carolina Rivers [34]

\begin{tabular}{|c|c|c|c|c|c|c|c|c|c|c|c|c|}
\hline \multirow{3}{*}{$\begin{array}{c}\text { Species } \\
\text { Humpback chub }\end{array}$} & \multirow{3}{*}{$\begin{array}{r}\begin{array}{r}\mathrm{n} \text { fish } \\
\text { aged }\end{array} \\
18^{*}\end{array}$} & & \multicolumn{3}{|c|}{$\begin{array}{l}\text { Six Parameters } \\
\text { Estimated }\end{array}$} & \multirow{3}{*}{$\begin{array}{c}\mathrm{n} \\
1.16\end{array}$} & \multirow{3}{*}{$\begin{array}{l}\mathrm{Qm} \\
1^{* *}\end{array}$} & \multirow{3}{*}{$\begin{array}{l}\text { Qc } \\
3.22\end{array}$} & \multicolumn{4}{|c|}{$\begin{array}{l}\text { Two Parameters Constrained } \\
\qquad(Q m=2, n=0.8)\end{array}$} \\
\hline & & $\mathrm{n}$ tag recaps & $\mathrm{H}$ & $\mathrm{m}$ & d & & & & $\mathrm{H}$ & $\mathrm{m}$ & $\mathrm{d}$ & Qc \\
\hline & & 4000 & 1.97 & 0.13 & 0.60 & & & & 1.85 & 0.42 & 0.58 & 3.88 \\
\hline Pygmy pikeminnow & 2621 & 2032 & 1.28 & 0.53 & 0.64 & 0.81 & 3.89 & 8.76 & 1.50 & 0.57 & 0.63 & 6.05 \\
\hline Rainbow trout & 308 & 658 & 20.16 & 8.06 & 0.52 & 0.62 & $1 * *$ & 1.73 & 8.87 & 1.40 & 0.57 & 3.60 \\
\hline $\begin{array}{l}\text { Largemouth bass } \\
\text { (Chassowiska) }\end{array}$ & 63 & 22 & 8.37 & 6.42 & 0.58 & 0.64 & 3.99 & 4.95 & 4.25 & 4.19 & 0.67 & 4.53 \\
\hline $\begin{array}{l}\text { Largemouth bass (Ho- } \\
\text { mossassa) }\end{array}$ & 47 & 44 & 5.79 & 1.10 & 0.32 & 0.66 & $1 * *$ & 4.17 & 5.85 & 5.22 & 0.67 & 3.66 \\
\hline
\end{tabular}

$$
\mathrm{dW} / \mathrm{dt}=\mathrm{HW}^{\mathrm{d}}-\mathrm{mW} \mathrm{W}^{\mathrm{n}}
$$

In bioenergetics modeling (e.g. the Wisconsin model, [7, 8]; [8]), $\mathrm{H}$ is typically articulated as a time-dependent product of temperature-dependent maximum feeding rate $\left(\mathrm{C}_{\max }\right)$, times proportion of maximum ration achieved (p), times constant assimilation efficiency, times 1-SDA where SDA represents specific dynamic action and active metabolic costs proportional to food intake rate. Assimilation efficiency here accounts for egestion and excretion losses, as well as the ratio of predator : prey energy densities. Standard metabolic rate
$\mathrm{mW}^{\mathrm{n}}$ is represented by the parameter $\mathrm{m}$, which varies with temperature according to some Q10 relationship. In such models, the anabolic rate $\mathrm{HW}^{\mathrm{d}}$ can be expressed as $\mathrm{HW}^{\mathrm{d}}=\mathrm{eR}$, where $\mathrm{R}$ is food intake rate (mass/time) or ration, and growth efficiency $\mathrm{e}$ is the product of assimilation efficiency times 1-SDA. Given estimates of $\mathrm{H}$ and $\mathrm{d}$, ration $\mathrm{R}$ can then be back-calculated simply as $\mathrm{R}=\mathrm{HW}^{\mathrm{d}} / \mathrm{e}$, or given estimates of $\mathrm{m}, \mathrm{n}$ and observed growth rates $\Delta \mathrm{W} / \Delta \mathrm{t}$ as $\mathrm{R}=\left(\Delta \mathrm{W} / \Delta \mathrm{t}+\mathrm{mW}^{\mathrm{n}}\right) / \mathrm{e}$. For such calculations, e is typically assumed to be in the range $\mathrm{e}=0.5-0.7$, but will vary depending on prey type and energy densities $[4,5]$. Note further that eq. (1) implies the asymptotic body weight 


$$
\mathrm{W}_{\infty}=\left(\frac{\mathrm{H}}{\mathrm{m}}\right)^{\frac{1}{\mathrm{n}-\mathrm{d}}}
$$

This relationship can be useful in constraining estimates of average $\mathrm{H}$ and $\mathrm{m}$ (and/or the power parameters $\mathrm{n}$ and $\mathrm{d}$ ) given observations on asymptotic body weight. Further, it implies that $n>d$ is a necessary condition for the model to predict a finite asymptotic weight (and length).

Providing body condition factor remains relatively stable over time, i.e. the "parameters" a,b in the length-weight relationship $\mathrm{W}=\mathrm{aL}^{\mathrm{b}}$ are constant, eq. (1) can be converted into a bioenergetics model for length $\mathrm{L}$ by noting that

$$
\mathrm{dL} / \mathrm{dt}=(\mathrm{dL} / \mathrm{dW})(\mathrm{dW} / \mathrm{dt})
$$

Noting that $\mathrm{L}=(\mathrm{W} / \mathrm{a})^{1 / \mathrm{b}}$ and substituting the derivative of this $(\mathrm{dL} / \mathrm{dW})$ along with eq. (1) into (3), elementary algebra shows that eq. (1) along with $\mathrm{W}=\mathrm{aL}^{\mathrm{b}}$ implies

$$
\mathrm{dL} / \mathrm{dt}=\alpha \mathrm{L}^{\delta}-\kappa \mathrm{L}^{\eta}
$$

where the parameters $\alpha, \delta, \kappa$, and $\eta$ are given in terms of the weight growth parameters $\mathrm{H}, \mathrm{m}, \mathrm{d}$, and $\mathrm{n}$ along with $\mathrm{a}, \mathrm{b}$ of the length-weight relationship by

$$
\begin{aligned}
& \alpha=a^{d-1} H / b \\
& \kappa=a^{n-1} m / b \\
& \delta=b d-b+1 \\
& \eta=b n-b+1
\end{aligned}
$$

Eq. (4) implies the asymptotic body length $\mathrm{L}_{\infty}=(\alpha / \kappa)^{1 /(\eta-\delta)}$, and the model predicts a finite asymptotic length only if $\eta>\delta$ Feeding rate $\mathrm{R}$ can be back calculated from the relationship $\mathrm{R}=\alpha \mathrm{abL} \mathrm{bd}^{\mathrm{e}}$. If incremental growth rate data $\Delta \mathrm{L} / \Delta \mathrm{t}$ are available (e.g. from short-term tag recaptures), a simple estimate of size-dependent feeding rate under the standard vonBertalanffy assumption that $\mathrm{n}=1$ is given by $\mathrm{R}=\left(\mathrm{baL}^{\mathrm{b}-}\right.$ $1 / \mathrm{e})(\Delta \mathrm{L} / \Delta \mathrm{t}+\kappa \mathrm{L})$.

As noted by Gurney and Nisbet (1998) [9] and Essington et al. (2001) [5], analytical solutions for L over time from (4) only exist in the special case $n=1$, i.e. standard respiration rate plus loss of reproductive products proportional to weight, and these solutions are called the "generalized Von Bertalanffy growth function (VBGF)" $[3,4]$. The further assumptions that $b=3$ and $d=2 / 3$ result in $\delta=0$ and $\eta=1$, and the integral of (4) over time is the standard von Bertalanffy growth function. Essington et al. (2001) [5] further note that estimation of $\alpha$ and $\kappa$ using the standard VBGF (for which $\kappa=K$ ) typically result in downward biased estimates of the bioenergetics parameters $\mathrm{m}$ and $\mathrm{H}$ (by solving eq. (5),(6) for these quantities given empirical estimates of $\alpha$ and $\kappa)$ if $d$ is in fact greater than $2 / 3$ (it is common in bioenergetics models to assume $\mathrm{d}$ is larger, e.g. 0.7) and/or $\mathrm{n}$ is less than 1.0 (It is common to assume $\mathrm{n}=0.8$ as reviewed in Clarke and Johnston (1999) [10], though Essington et al. (2001) [5] present metaanalysis data suggesting $n=1$ is a better default assumption when reproductive expenditures are considered).

\section{ESTIMATION OF BIOENERGETICS POWER PA- RAMETERS FROM LENGTH INCREMENT DATA}

Growth curves generated from numerical integration of eq. (4) with $\delta \neq 0$ and $\kappa \neq 1.0$ (e.g. $d=0.7, n=0.8$ ) still look much like the classic VBGF, and can be fitted very closely by the VBGF. That is, data on body lengths at age typically cannot be used to estimate the power parameters $\delta$ and $\eta$, even if the data have essentially no random variation due to measurement errors and individual variation in the $\mathrm{H}$ and $\mathrm{m}$ parameters. $\mathrm{H}$ and $\mathrm{m}$ can only be estimated from age-length data if the $d$ and $n$ parameters (or $\delta$ and $\eta$ ) are known in advance, e.g. from laboratory bioenergetics studies.

However, there is at least in principle some possibility of extracting information on $\mathrm{d}$ and $\mathrm{n}$ from examination of data on the relationship between growth rate $(\mathrm{dL} / \mathrm{dt})$ and length, as is collected in tag-recapture studies. Tag-recapture studies result in a set of body length measurements $\mathrm{L}_{1}, \mathrm{~L}_{1}, \Delta \mathrm{t}$ (length at tagging, length at recapture, time between tagging and recapture). One simple way to examine such data is simply to plot the approximate growth rates $\Delta \mathrm{L} / \Delta \mathrm{t}=\left(\mathrm{L}_{2}-\mathrm{L}_{1}\right) / \Delta \mathrm{t}$ against the lengths at tagging. Providing all or most of the $\Delta \mathrm{t}$ are short (less than 2 yrs.), such plots will show evidence of concave curvature (higher $\mathrm{dL} / \mathrm{dt}$ at for small fish than predicted from slope of the $\mathrm{dL} / \mathrm{dt}$ vs $\mathrm{L}$ relationship for larger fish) if $d<2 / 3$ and/or $n<1.0$, whereas the VBGF predicts a linear relationship with slope $-\kappa$ (Fig. 1). However, measurement errors in $\mathrm{L}_{1}$ and $\mathrm{L}_{2}$ along with individual variation in $\alpha$ (i.e. in maximum body lengths $\mathrm{L}_{\infty}$ ) typically conspire to make any curvature difficult to see or to demonstrate statistically.

A more sophisticated approach to analysis of tagrecapture data is to use some generalization of the Fabens (1965) method. In its original form, that method involves nonlinear estimation of $L_{\infty}$ and $\kappa$ under the assumption $d=2 / 3$ and $n=1$, by noting that length increments under the VBGF should vary on average as $\mathrm{L}_{2}=\mathrm{L}_{1}+\left(\mathrm{L}_{\infty}-\mathrm{L}_{1}\right)[1-\exp (-\kappa \Delta \mathrm{t})]$. Various statistical improvements on the original Fabens regression method have been developed [11-13] by looking at how the variances of the individual $\mathrm{L}_{2}-\mathrm{L}_{1}$ observations ought to depend on individual variations in $\mathrm{L}_{\infty}$ and on $\kappa \Delta \mathrm{t}$. These methods have used the assumption that the "physiological" parameter $\kappa$ ought not to vary much among individuals subject to similar thermal environments, while the "ecological" (feeding) parameter $\alpha$ ought to be highly variable due to individual differences in food availability and risk taking behavior [14]. It is easily shown that if the length observations are measured with normally distributed errors with variance $\sigma_{m}^{2}$ and individual $L_{\infty}$ values are normally distributed with variance $\sigma_{L}^{2}$ (and sampled $L_{\infty}$ values are independent of sampled $L_{1}$ values), then the conditional distribution of each $\mathrm{L}_{2}$ observation, given observed $\mathrm{L}_{1}$ and given mean $\mathrm{L}_{\infty}$ and $\kappa$, is normal with variance

$$
\mathrm{V}_{\mathrm{i}}=\sigma_{\mathrm{m}}^{2}\left(1+\mathrm{e}^{-2 \mathrm{\kappa} \Delta \mathrm{ti}}\right)+\sigma_{\mathrm{L}}^{2}\left(1-\mathrm{e}^{-\mathrm{K}^{\Delta \mathrm{ti}}}\right)^{2}
$$

Under this variance assumption, maximum likelihood estimates of $L_{\infty}, \kappa, \sigma_{m}^{2}$, and $\sigma_{L}^{2}$ can be found (in principle) by maximizing the concentrated log-likelihood function

$$
\ln L=-(\mathrm{N} / 2) \mathrm{SS}-0.5 \Sigma_{\mathrm{i}} \ln \left(\mathrm{V}_{\mathrm{i}}\right)
$$

where SS is the sum over recapture observations $i$ of the inverse-variance-weighted deviations $D_{i}{ }^{2} / V_{i}$ and the deviation $\mathrm{D}_{\mathrm{i}}$ for each observation is given by

$$
\mathrm{D}_{\mathrm{i}}=\mathrm{L}_{2 \mathrm{i}}-\mathrm{L}_{1 \mathrm{i}}-\left(\mathrm{L}_{\infty}-\mathrm{L}_{1 \mathrm{i}}\right)\left[1-\exp \left(-\kappa \Delta \mathrm{t}_{\mathrm{i}}\right)\right] \text {. }
$$


Estimation experiments with simulated data indicate that this method should work quite well, except at distinguishing the variance components $\sigma_{\mathrm{m}}^{2} \sigma_{\mathrm{L}}^{2}$; typically one of these components must be specified a priori in order to obtain a reliable estimate of the other component. Unfortunately, no comparable statistical procedure can be developed for the general length dynamics model defined by eq. (4), since no analytical expression exists for the observation variances $V_{i}$.

The estimation procedure defined by eqs. (9)-(11) can be readily used with the general growth model (eq. 4), provided we are willing to first fit the tag-recapture data to the specialized von Bertalanffy and to assume the variance estimates $V_{i}$ (eq. 9) from that fitting are reasonable approximations for variances implied by the more general model. The only change needed then is to calculate the $\mathrm{D}_{\mathrm{i}}$ by numerically integrating eq. (4) to provide predicted changes in length:

$$
\mathrm{D}_{\mathrm{i}}=\mathrm{L}_{2 \mathrm{i}}-\int_{\mathrm{t}=\mathrm{t}_{1}}^{\mathrm{t}=\mathrm{t}_{1}+\Delta \mathrm{t}}\left(\alpha \mathrm{L}^{\delta}-\kappa \mathrm{L}^{\eta}\right)
$$

That is, we take the predicted value of $\mathrm{L}_{2 \mathrm{i}}$ to be the integral of $\mathrm{dL} / \mathrm{dt}$ from the time of tagging for fish $i t_{1 i}$ to the time of recapture $\mathrm{t}_{1 \mathrm{i}}+\Delta \mathrm{t}_{\mathrm{i}}$, where $\mathrm{dL} / \mathrm{dt}$ is given by the differential eq. (4) with initial $\mathrm{L}=\mathrm{L}_{1 \mathrm{i}}$. This numerical integration is very simple to perform in spreadsheets and statistical packages like R. Note that the estimation procedure can then involve up to 6 unknown parameters $\left(\alpha, \delta, \kappa, \eta, \sigma_{m}^{2}, \sigma_{L}^{2}\right)$, though analysis on simulated data shows that not only the variance components $\sigma_{\mathrm{m}}^{2}, \sigma_{\mathrm{L}}^{2}$ are difficult to separate but also effects of the power parameters $\delta, \eta$ since departures of either of these from the VBGF assumption can lead to any curvature that may be visible in the $\Delta \mathrm{L} / \Delta \mathrm{t}$ vs $\mathrm{L}$ (and length increment to recapture) data.

\section{ACCOUNTING FOR SEASONAL VARIATION IN FEEDING AND METABOLIC RATES}

Size at age and growth increment data from tagging are typically analyzed under the assumption that $\alpha$ and $\kappa$ (or $\mathrm{L}_{\infty}, \mathrm{K}$ ) have been constant over time. This assumption may be reasonable for examination of interannual changes, but it is badly violated in studies where growth data are collected on a seasonal basis in temperate systems.

Nothing in the general numerical integration forms eq. (1)-(4) prevents us from treating $\mathrm{H}$ and $\mathrm{m}$ as time variable. For example we can calculate them using temperaturedependent multipliers $f_{c}\left(T_{i}(t)\right)$ and $f_{m}\left(T_{i}(t)\right)$ where $f_{c}$ and $f_{m}$ represent relative feeding and metabolic rates as functions of the time course of water temperatures $T_{i}(t)$ likely experienced by fish $\mathrm{i}$, using the more general growth model

$$
\mathrm{dW} / \mathrm{dt}=\mathrm{HW}^{\mathrm{d}} \mathrm{f}_{\mathrm{c}}(\mathrm{T}(\mathrm{t}))-\mathrm{mW}^{\mathrm{n}} \mathrm{f}_{\mathrm{m}}(\mathrm{T}(\mathrm{t}))
$$

It is not generally possible to estimate the parameters of $f_{c}$ and $f_{m}$ just from observations of weight growth rates, but we can certainly use functions with parameter values estimated from more complex bioenergetics analyses. In fact, ignoring such time dependence in $\alpha$ and $\kappa$ can cause severe bias in parameter estimation where the tagging times $t_{i}$ are seasonally concentrated and when the $\Delta \mathrm{t}_{\mathrm{i}}$ are relatively short, e.g. when the fish are all captured and recaptured during a summer sampling season when both $\alpha$ and $\kappa$ are likely to be well above the annual average.

For fitting data on seasonal weight changes and tagrecapture weight data using eq. (13), we recommend using the following relatively simple forms for $\mathrm{fc}$ and fr:

$$
\begin{aligned}
& \mathrm{f}_{\mathrm{c}}(\mathrm{T})=\mathrm{Q}_{\mathrm{c}}{ }^{(\mathrm{T}-10) / 10} \mathrm{e}^{-\mathrm{g}(\mathrm{T}-\mathrm{Tm})} /\left(1+\mathrm{e}^{\mathrm{g}(\mathrm{g}-\mathrm{Tm})}\right) \\
& \mathrm{f}_{\mathrm{m}}(\mathrm{T})=\mathrm{Q}_{\mathrm{m}}{ }^{(\mathrm{T}-10) / 10}
\end{aligned}
$$

Here, $Q_{m}$ and $Q_{c}$ are $Q 10$ coefficients, typically around 2.0 for $\mathrm{Q}_{\mathrm{m}}[15]$ and often much larger for $\mathrm{Q}_{\mathrm{c}}$ since $\mathrm{Q}_{\mathrm{c}}$ typically represents increase with $T$ in both digestion rates and food availability. $T_{a}$ represents annual average temperature (so that $\mathrm{H}$ and $\mathrm{m}$ represent feeding and metabolic rates at $\mathrm{T}=10^{\circ} \mathrm{C}$ ). The exponential ratio in eq. (14) represents drop in feeding at high temperatures; $\mathrm{T}_{\mathrm{m}}$ represents the temperature at which feeding rate drops to half the value predicted from $Q_{c}$, and g represents how rapidly feeding drops off as $T_{m}$ is approached.

We can also write a relatively simple bioenergetics model like eq. (13) for length growth by using eq. (4), which we call the CA (continuous allocation) model. But this formulation must be used with care since it is often unwise to assume constant length-weight allometry (constant a,b in $\left.\mathrm{W}=\mathrm{aL}^{\mathrm{b}}\right)$ to back-calculate predicted length changes from integration of eq. (13) for cases where weight changes have not been measured. The problem with such a simple transformation is that body condition (as measured by $a, b$ ) is likely to change with seasonal changes in feeding opportunities and loss of weight (but not length) to reproductive products. We address the prediction of length changes for eq. (13) in the next section.

However, we note in passing that for cases where body condition does not show strong seasonal variation, body length dynamics are expected to follow eq. (4) with $f_{c}(T)$ multiplying $\alpha$ and $f_{m}(T)$ multiplying $\kappa$. For such cases, diagnostic plots of $\Delta \mathrm{L} / \Delta \mathrm{t}$ from seasonal tagging data (e.g. over summer recaptures versus over winter recaptures) should show an interesting feature provided temperatures are always well below $\mathrm{T}_{\mathrm{m}}$. Namely, the X-intercepts of the seasonal plots (estimates of $\left.\mathrm{L}_{\infty}\right)$ should vary approximately as $\left(\mathrm{Q}_{\mathrm{c}} / \mathrm{Q}_{\mathrm{m}}\right)$ (T-Ta) 110 and should not vary at all if $\mathrm{Q}_{\mathrm{c}}=\mathrm{Q}_{\mathrm{m}}$. An example of this effect is shown in Fig. (1) for rainbow trout (Oncorhynchus mykiss) from Cabin Lake, Alberta. Summer mean temperature is below $20^{\circ} \mathrm{C}$ in this lake, and winter temperature averages around $3.5^{\circ} \mathrm{C}$, so temperature is always well below the typical $\mathrm{T}_{\mathrm{m}}$ for rainbow trout. The plots of $\Delta \mathrm{L} / \Delta \mathrm{t}$ from over-summer tag recaptures show the similar $\mathrm{L}_{\infty}$ as for plots of over-winter recaptures, indicating $\mathrm{Q}_{\mathrm{c}} \approx \mathrm{Q}_{\mathrm{m}}$. Fits to the tagging data using numerical integration of eq. (4) with $f_{c}$ and $f_{m}$ multipliers, and $\mathrm{Q}_{\mathrm{c}}, \mathrm{Q}_{\mathrm{m}}$ allowed to vary in the fitting give $\mathrm{Q}_{\mathrm{c}} \approx 3.0$ and $\mathrm{Qm} \approx 2.6$, again implying a seasonal change of only $10-15 \%$ in $\mathrm{L}_{\infty}$.

It is not just seasonal temperature changes that can create apparent changes in $\alpha$ and $\kappa$, or make the size-dependence power parameters $\delta$ and $\eta$ appear differ strongly from $2 / 3$ and 1.0. In particular, it is not unusual for fish to show ontogenetic habitat shifts from relatively warm juvenile nursery areas to cooler adult residence areas; for example the potadromous humpback chub (Gila cypha) in the Grand Can- 


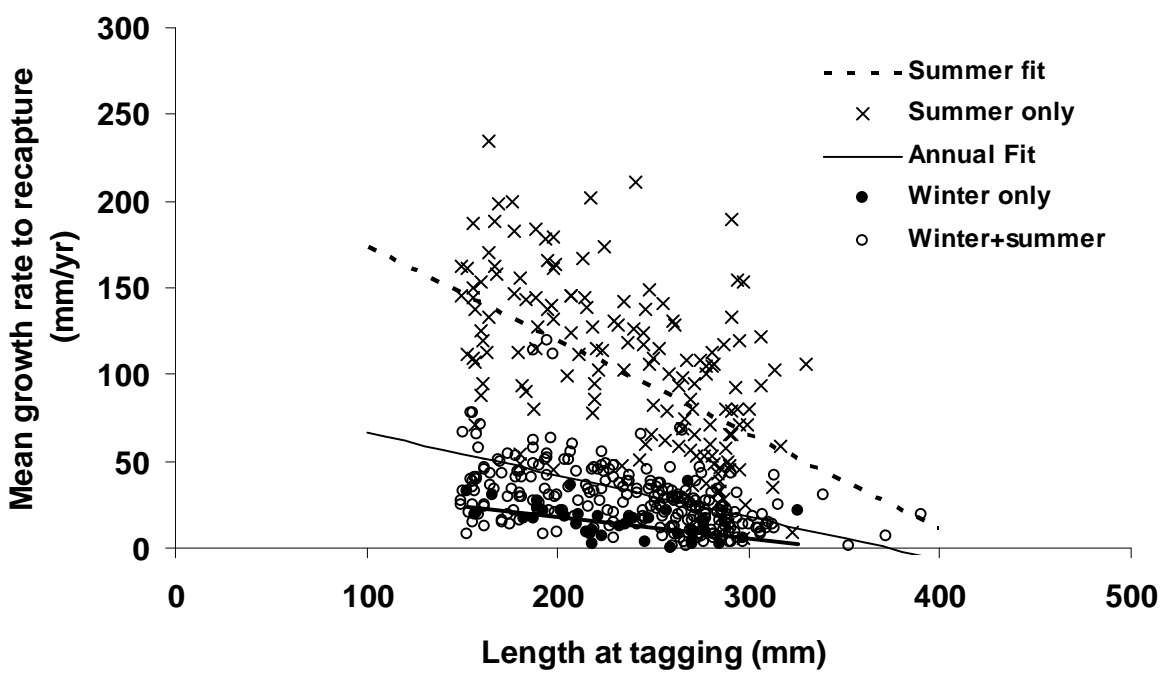

Fig. (1). Plots of growth rates (change in length per time, $\Delta \mathrm{L} / \Delta \mathrm{t}$ ) for tagged fish are predicted to decline linearly with body size under the vonBertalanffy model, with slope equal to 0.33 times the annual metabolic rate per body weight. These data for spaghetti tagged rainbow trout from Cabin Lake, Alberta show apparently linear relationships with much lower metabolic rate for overwinter recaptures.

yon, Arizona, typically begins to move around maturity (age $3-4,250 \mathrm{~mm}$ body length) from relatively warm nursery areas in the Little Colorado River into the much colder waters (due to an upstream dam) of the Colorado River mainstem for most of each year. For this population, diagnostic plots of dL/dt versus L (Fig. 2) show a "kink" at about the size where migration to the mainstem begins, with younger fish showing apparently higher $\kappa$ and lower $\mathrm{L}_{\infty}$ values than older fish. Estimation using eq. (12) on over 16000 tag-recapture observations [15] results in $\delta=-1.25$ and $\eta=-0.13(\mathrm{~d}=0.25$, $\mathrm{n}=0.62$ ), both unrealistically small and indicative of a strongly curved $\mathrm{dL} / \mathrm{dt}$ vs L relationship independent of temperature effects. Even when $\mathrm{n}$ is constrained to 1.0 (implying $\eta=1$, Generalized von Bertalanffy model), the estimated $d$ is unrealistically low $(\mathrm{d}=0.10, \delta=-1.69)$. But effects on growth parameters of the habitat shift could easily be misinterpreted as evidence for power parameters differing from $2 / 3$ and 1 , when in fact it is not possible to decide from the length increment data whether or not the fish follow a simple VBGF within each of the two life history stanzas. Fortunately, for purposes of avoiding downward bias in estimation of food consumption rates as Essington et al. (2001) [5] describe, it does not really matter whether the apparent low $\delta$ and $\eta$ are actually due to size allometry or to size-dependent changes in habitat temperatures; the net effect of either on calculation of $\mathrm{R}$ is the same.

\section{ACCOUNTING FOR PERIODS OF ZERO LENGTH GROWTH AND ALLOCATION TO GONADAL PRODUCTS (DYNAMIC CHANGE IN CONDITION FACTOR)}

This section develops a more complex model that we call SRSA (seasonal reproduction, skeletal allocation) to represent the more complex length and weight dynamics implied by seasonality in loss of energy to reproductive products and variable allocation of food intake to growth in length (skeletal growth) versus weight. A key assumption in the non- seasonal CR model above for extracting information about bioenergetics parameters from length data is that the lengthweight relationship is stable over time, i.e. that body fatness or condition factor (as measured by indices like $\mathrm{W} / \mathrm{L}^{\mathrm{b}}$ ) remains stable as assumed by Gurney et al. (2007) [9]. This assumption may be reasonable for examining interannual growth patterns, but it can be badly violated in analysis of seasonal data due to dynamic changes in body weight (e.g. release of reproductive products, decline in weight during winter food shortages) that are not accompanied by decreases in length. To account for such changes, it is possible to model the allocation of growth resources to at least two components of body mass, "structural" tissue (bone, cartilage, etc.) that is not metabolized and "reserve" or metabolizable tissue (fat, muscle, etc.) that may be used to satisfy metabolic demand during periods when food intake cannot satisfy those demands [17-20]. Body length is then represented as a power function of the structural tissue mass. A key advantage of this approach is that it avoids potential misinterpretation of age-length data in cases where length appears to decrease with age for older fish (e.g. Fig. 2 in the Hayes et al. 2000 analysis of a New Zealand brown trout population [1]); such decreases are most likely due to selective mortality of larger individuals rather than loss in length by fish that are declining in body weight. A further advantage is in allowing explicit representation of energy allocation to reproduction, with the possibility of using reproductive energy allocation parameters predicted from evolutionary theory [20].

Suppose we partition body weight $\mathrm{W}$ into two components, structural weight $\mathrm{W}_{\mathrm{s}}$ and metabolizable weight $\mathrm{W}-\mathrm{W}_{\mathrm{s}}$. Then the dynamics of $\mathrm{W}_{\mathrm{s}}$ can be represented by either the Broeckhuizen et al. (1994) [17] assumption that a proportion $\mathrm{f}_{\mathrm{s}}$ of total growth rate is allocated to $\mathrm{W}_{\mathrm{s}}$ provided total growth is greater than zero:

$$
\mathrm{dW}_{\mathrm{s}} / \mathrm{dt}=\mathrm{f}_{\mathrm{s}} \operatorname{Max}\left(0, \mathrm{H}^{\prime} \mathrm{W}_{\mathrm{s}}^{\mathrm{d}}-\mathrm{m} \mathrm{W}^{\mathrm{n}}\right)
$$




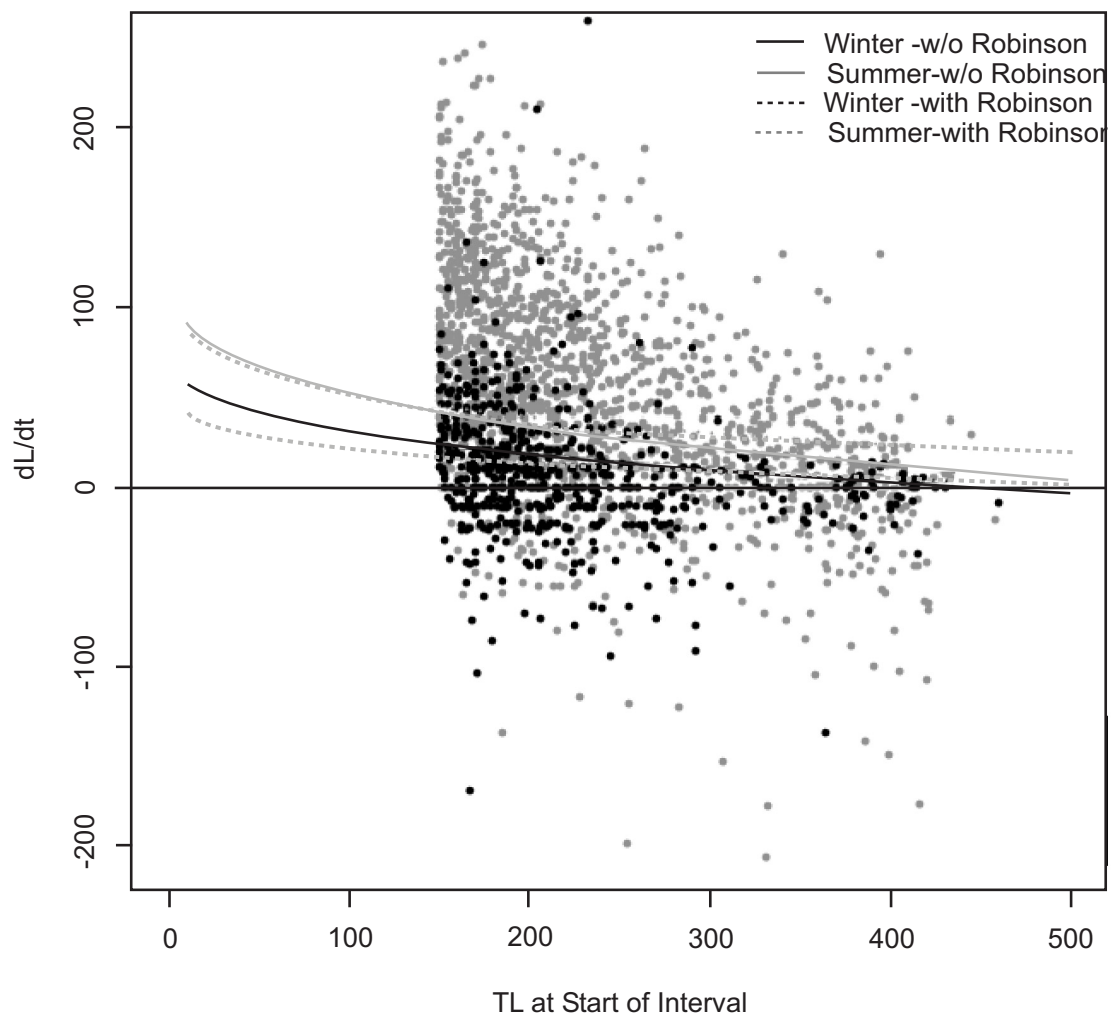

Fig. (2). Growth rate $(\Delta \mathrm{L} / \Delta \mathrm{t})$ based on PIT tag returns of humpback chub from the Little Colorado River spawning stock, Colorado River, Grand Canyon, Arizona. Note apparent change in metabolic rate (slope of regression relationship) at 200-300mm, the size-age range when these fish begin to emigrate from the relatively warm Little Colorado River to spend much of the year in much colder mainstem Colorado River water. General growth model (eqs. 13-15) fits are shown with and without including auxiliary information on size at age for fish too small $(<150 \mathrm{~mm})$ to PIT tag; auxiliary growth data from [16].

or the Jones et al. (2002) [19] assumption that a fraction $\mathrm{f}_{\mathrm{s}}$ of net assimilated food intake (eR) is allocated to structural growth whether or not body weight is growing:

$$
\mathrm{dW}_{\mathrm{s}} / \mathrm{dt}=\mathrm{f}_{\mathrm{s}} \mathrm{eR}=\mathrm{f}_{\mathrm{s}} \mathrm{H}^{\prime} \mathrm{W}_{\mathrm{s}}^{\mathrm{d}}
$$

Note that for both of these cases, we need to assume that the food intake rate component of $\mathrm{dW} / \mathrm{dt}$ (e.g. in eq. 13) is proportional to a power of $\mathrm{W}_{\mathrm{s}}$ rather than total $\mathrm{W}$ (which requires rescaling of $\mathrm{H}$ from eq. 1 and 13 to $\mathrm{H}^{\prime}=\mathrm{H} / \mathrm{f}^{*}{ }_{\mathrm{s}}{ }_{\mathrm{d}}$ where $\mathrm{f}_{\mathrm{s}}$ is the "normal" ratio of $\mathrm{w}_{\mathrm{s}}$ to $\mathrm{w}$ ); otherwise we would incorrectly predict (using $\mathrm{Hw}^{\mathrm{d}}$ ) that food intake rate should decrease even after "normal" loss events of metabolizable tissue (such as release of reproductive products), which do not in fact impair feeding or digestive ability. Note further that eq. (13) predicts standard metabolic rate from total W rather than metabolizable tissue weight $\mathrm{W}-\mathrm{W}_{\mathrm{s}}$; this (technically incorrect) simplification allows use of laboratory data on $\mathrm{m}, \mathrm{n}$ measured as a function of total weight $\mathrm{W}$, and is a reasonable approximation except in cases of near starvation (very low $\left(\mathrm{W}-\mathrm{W}_{\mathrm{s}}\right)$ relative to the normal $\mathrm{W}_{\mathrm{s}}=\left(1-\mathrm{f}_{\mathrm{s}}\right) \mathrm{W}$ condition).

Eqs. (16) and (17) place the burden of predicting changes in body condition, as indexed by $\mathrm{W}_{\mathrm{s}} / \mathrm{W}$, on predicting the fraction $f_{s}$ of net intake allocated to growth of $W_{s}$. Simply assuming constant $\mathrm{f}_{\mathrm{s}}=\mathrm{f}_{\mathrm{s}}$ in eq. (13), independent of age or total weight, does result in weak apparent "compensation" in the form of reduced allocation to length growth when food intake is low and/or metabolic rate is high, but does not in general predict rapid or full restoration of body condition for older fish after loss of weight to reproductive products. Eq. (17) further requires that $f_{s}$ be made a decreasing function of total body weight even when there are no disturbances such as release of eggs, according to some function of the general form

$$
\mathrm{f}_{\mathrm{s}}=\mathrm{f}^{*}\left(1-(\mathrm{m} / \mathrm{H}) \mathrm{W}^{\mathrm{n}-\mathrm{d}}\right)
$$

Without this progressive correction for larger fish, allocating a constant fraction $f_{s}$ of intake to non-metabolized tissue would result in progressive increase with age in the $\mathrm{W}_{\mathrm{s}} / \mathrm{W}$ ratio, i.e. in fish becoming progressively thinner with age. We recommend modeling "compensatory" adjustments in $\mathrm{f}_{\mathrm{s}}$ when predicted $\mathrm{W}_{\mathrm{s}} / \mathrm{W} \neq \mathrm{f}_{\mathrm{s}}$, as suggested by $[17,18]$, by multiplying $\mathrm{f}_{\mathrm{s}}$ at each moment (or the weight-adjusted $\mathrm{f}_{\mathrm{s}}$ of eq. (18) at each moment when $\mathrm{W}_{\mathrm{s}}$ is modeled by eq. 17) by a feedback function $\mathrm{f}_{\mathrm{s}}=\mathrm{f}_{\mathrm{s}} \mathrm{C}\left(\mathrm{W}_{\mathrm{s}}, \mathrm{W}\right)$, where $\mathrm{C}=1$ for $\mathrm{W}_{\mathrm{s}} / \mathrm{W}=\mathrm{f}_{\mathrm{s}}$ and varies with "thinness" $\mathrm{W}_{\mathrm{s}} / \mathrm{W}$ as

$$
\mathrm{C}\left(\mathrm{W}_{\mathrm{s}}, \mathrm{W}\right)=2 /\left[1+\exp \left(-\theta\left(\mathrm{f}_{\mathrm{s}}^{*} \mathrm{~W}-\mathrm{W}_{\mathrm{s}}\right)\right)\right]
$$

This is a logistic function that sets $\mathrm{C}$ to a maximum of 2 (i.e. allocates up to double the intake resources to skeletal growth when the fish is plump), and drops $\mathrm{C}$ toward 1.0 as Ws/W approaches $\mathrm{f}^{*}$ s with steepness set by $\theta$. This function is essentially a simple approximation to more complex state dependent allocation rules that can be derived using dynamic programming methods [21]. 


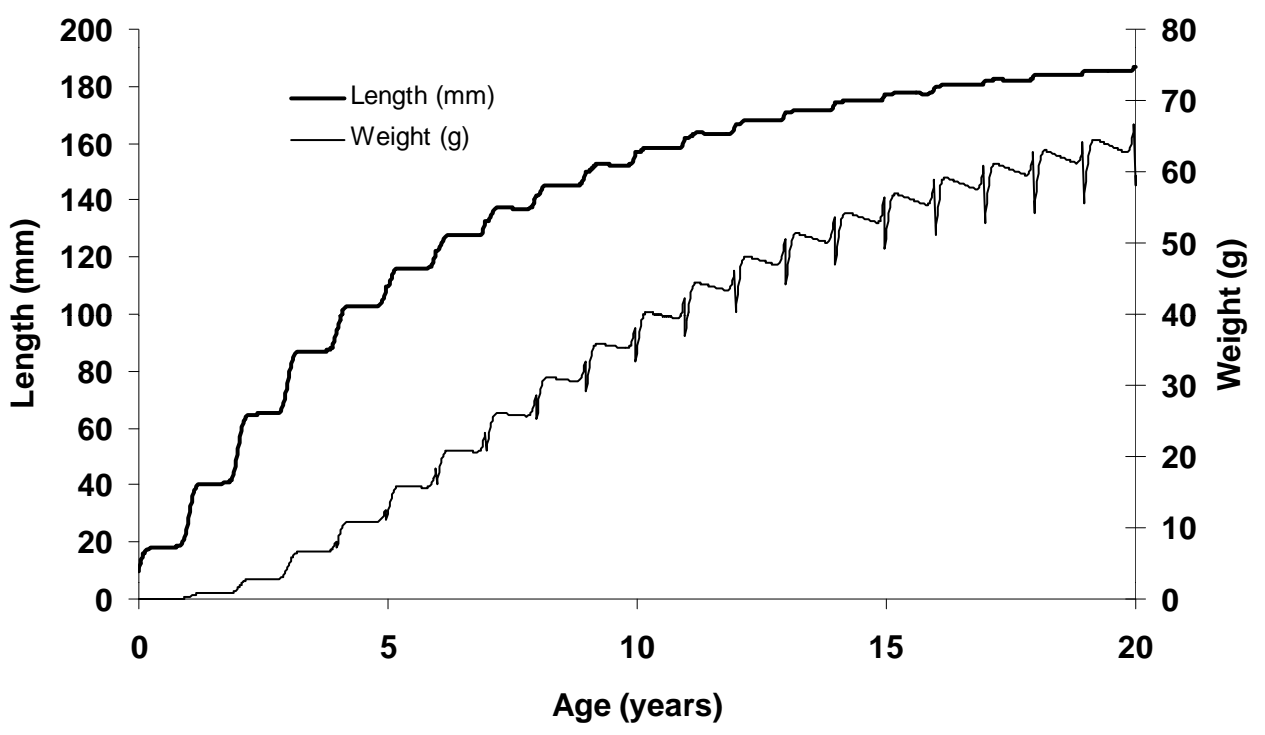

Fig. (3). Simulated growth in length and weight for a pikeminnow with parameter values estimated from pygmy populations of the Bonaparte Plateau, British Columbia. Note predicted winter weight loss and loss in weight of larger fish at time of spawning (early July).

When $\theta$ is large ( $>50$; implying highly sensitive response of $\mathrm{f}_{\mathrm{s}}$ to deviations from "normal" $\mathrm{W} / \mathrm{W}_{\mathrm{s}}$ ), eq. (16) and (17) with $\mathrm{f}_{\mathrm{s}}$ predicted from eq. (19) predict essentially identical trajectories of growth in $\mathrm{W}$ and $\mathrm{L}$ (assuming $\mathrm{L}=\mathrm{a}^{\prime} \mathrm{W}_{\mathrm{s}}{ }^{1 / 3}$ ), as shown for a simulated pikeminnow (Ptychocheilus oregonensis) example in Fig. (3). For this example, we assumed strong seasonal temperature modeled by a sin curve ( $\max$ $\mathrm{T}=16{ }^{\circ} \mathrm{C}$, min $\left.\mathrm{T}=4{ }^{\circ} \mathrm{C}\right), \mathrm{Q}_{\mathrm{c}}=2.5$ in eq. 14 to create negative weight change at low temperatures, and we subtracted $0.15 \mathrm{~W}$ from weights of older fish at the start of simulated summer, to simulate release of reproductive products $(15 \%$ of body weight).

Note that the example simulation (Fig. 3) shows declining body condition with age, i.e. an overall $b<3.0$. This is typically seen with the simple feedback rule eq. (19), and may be realistic for some fish species [22]. A more complex rule than eq. (19) is needed to represent the possibility of $b>3.0$, i.e. some fish like carp tend to fatten as they age rather than never quite making up for weight losses associated with reproduction and seasonal food shortage (or seasonal high metabolic cost). A simple way to represent such allocation strategies is to modify the exponent term of eq. (19) downward for high $\mathrm{W}$, i.e. to make $\mathrm{f}_{\mathrm{s}}$ a decreasing function of $\mathrm{W}$, by multiplying it in the exponent by a factor like $\left(1-\mathrm{W} / \mathrm{W}_{\infty}\right)^{0.1}$ (a low power like 0.1 in this multiplier causes the modified target $\mathrm{f}^{*}{ }_{\mathrm{s}}$ to decrease only for larger fish that are approaching $\mathrm{W}_{\infty}$ ).

Eqs. (13)-(15) and (16) or (17) plus (18) and (19) define the complete SRSA seasonal bioenergetics model for growth in body weight and length if length is assumed to be a simple function of structural weight (e.g. $\mathrm{L}=\mathrm{a}^{\prime} \mathrm{W}_{\mathrm{s}}{ }^{1 / 3}$ ) and if the normal structural weight proportion $\mathrm{f}^{*}$ s is known (or assumed to be any small proportion like 0.1 ). In principle this model can be fitted to size-time and size-increment data, given seasonal temperature patterns $\mathrm{T}(\mathrm{t})$ so as to estimate up to 9 parameters $\left(\mathrm{H}, \mathrm{m}, \mathrm{d}, \mathrm{n}, \mathrm{Q}_{\mathrm{m}}, \mathrm{Q}_{\mathrm{c}}, \mathrm{g}, \mathrm{T}_{\mathrm{m}}\right.$, and $\left.\theta\right)$. However, as noted above it is typically not possible to estimate both of the power parameters $\mathrm{d}$ and $\mathrm{n}$, and it is further reasonable based on the metaanalysis in $[5,10]$ to assume $0.8 \leq n \leq 1.0$, and on the metaanalysis of Clarke and Johnston (1999) [10] to assume $1.8 \leq \mathrm{Q}_{\mathrm{m}} \leq 2.4$. We recommend initially fixing these parameters at $\mathrm{n}=0.8$ (or 1.0 if weight loss to reproduction is ignored), $Q_{m}=2$, then examining whether other parameter estimates, particularly $\mathrm{d}$ and $\mathrm{Q}_{\mathrm{c}}$, appear to be reasonable (see humpback chub case above for an example of apparently unreasonable $\mathrm{d}$, caused by systematic change in water temperature with age and weight). In many cases, it is also reasonable to set $\mathrm{g}$ to some large value (e.g. 10) and $\mathrm{T}_{\mathrm{m}}$ to well above the maximum observed temperature, i.e. to assume that temperatures never exceed the optimum for growth; it is easy to check for violation of this assumption, by examining changes unrelated to reproduction in body condition at high temperatures (declining condition at high $\mathrm{T}$ is an indication that $\mathrm{T}$ is not far from $\mathrm{T}_{\mathrm{m}}$, implying $\mathrm{T}_{\mathrm{m}}$ cannot be ignored). So in "best" case situations, it should be possible to reduce the number of parameters to be estimated to 5 , or even 4 if $\theta$ is assumed large.

As a case example of using this model for a species that shows large, annual energy losses to reproduction, we fit it to data on brown trout from the Maruia River, New Zealand in Hayes et al. (2000) [1], and compared its predictions to the results of their complex bioenergetics model that included predictions of prey availability, search, and consumption. Hayes et al. note that mature brown trout (ages 4+) lose up to $46 \%$ of their energy content at spawning, so that growth virtually ceases after maturation and older fish show declines in both length and weight (Fig. 4). Hayes et al. do not show the details of their seasonal energy content predictions, but presumably their calculations have the same sharp drop in energy content at spawning times for older fish as shown for our model. Lacking seasonal growth data to estimate Q10s, we used their estimates of $\mathrm{Q}_{\mathrm{m}}=7.69$ and $\mathrm{Q}_{\mathrm{c}}=5.53$ from Elliott's (1976) [23] studies, set $\mathrm{n}=1$, and estimated $\mathrm{H}, \mathrm{m}$, and $\mathrm{d}$ by fitting to their length and weight data using a simple weighted least squares criterion (each data point weighted by inverse of expected variance due to measurement errors and individual variation in asymptotic body size). We manually 


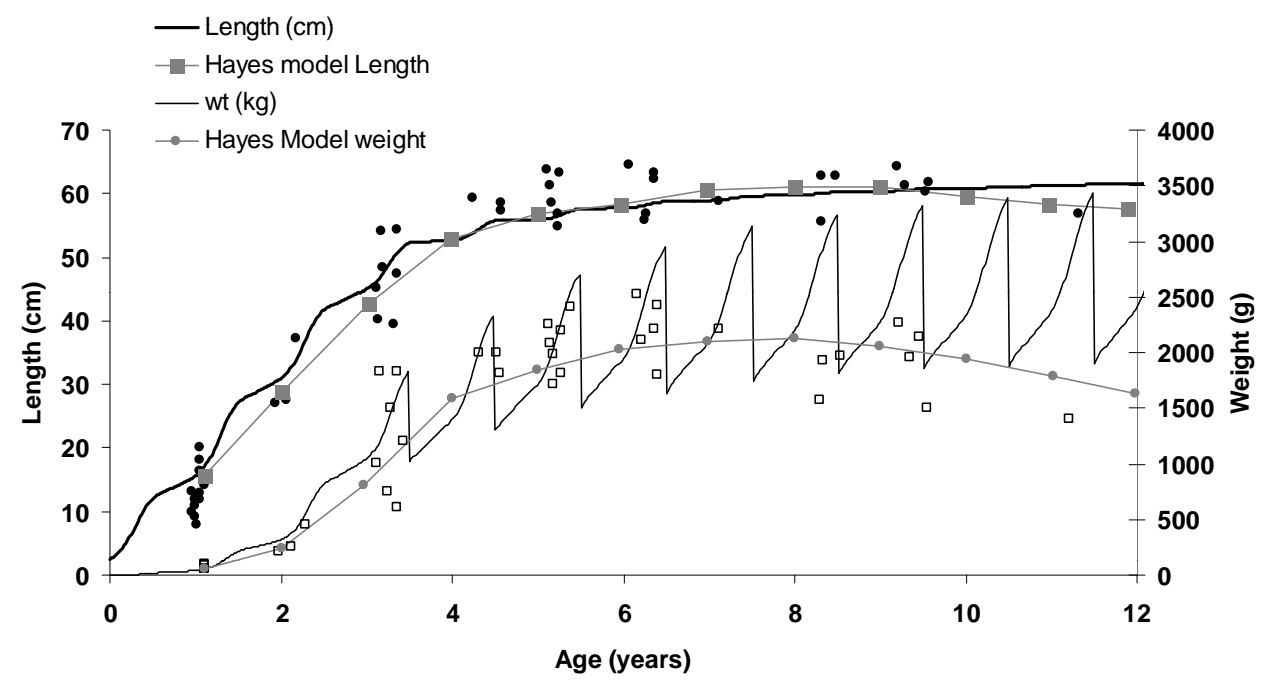

Fig. (4). Simulated growth in length and weight for New Zealand brown trout, compared to model predictions by Hayes et al. (2000) [1]. Data and model results extracted from Fig. 2 in Hayes et al.

varied the allocation parameters $\theta$ and $\mathrm{W}_{\infty}$ to see if we could obtain declines in pre-reproductive body weight with age, but we were unable to find any parameter combination that predicted such declines while still fitting the data by fitting $\mathrm{H}, \mathrm{m}$, and $\mathrm{d}$. Our $\mathrm{H}$ and $\mathrm{m}$ estimates agree fairly well with Hayes et al. in predicting feeding rates and in predicting about $20 \%$ of energy input allocated to size-dependent (standard) metabolism, and $\mathrm{d}=0.76$ is essentially identical to Elliot's (1976) [23] estimate. However, our assumed $n=1.0$ is much higher than Elliot's estimate of 0.77 ; assuming $n=0.77$ led to grossly unrealistic estimates of $\mathrm{m}$ and overestimates of weights at older ages). We do not predict declining length or weight at older ages, and we suspect that observed declines in length and weight are indicative of selective mortality of larger or faster-growing individuals rather than negative energy balance for older individuals, a possibility that Hayes et al. admitted as well.

ESTIMATION OF INDIVIDUAL GROWTH DEVIATIONS AND AGES FROM LENGTH INCREMENT DATA FOR SEASONALLY REPRODUCING SPECIES

Wang et al. (1995) [24] and Wang (1998) [25] noted that individual asymptotic body lengths and apparent ages at tagging can be estimated from length at tagging, length increment, and time to recapture when all individuals have the same metabolic parameter (von Bertalanffy K) but differ in $\mathrm{L}_{\infty}$. However, these estimates assume no measurement errors in $\mathrm{L}_{1 \mathrm{i}}$ and $\mathrm{L}_{2 \mathrm{i}}$, and also assume that animals can be of any age at tagging (continuous reproduction). For seasonally reproducing species, each individual can only be one of a discrete set of ages, so that the Wang method may produce nonsense ages for many individuals when length measurement errors are large. Correcting these problems leads to a likelihood function for the $\mathrm{L}_{1 \mathrm{i}}, \mathrm{L}_{2 \mathrm{i}}$ measurements that is less prone to bias than eq. (10), and at the same time provides an estimate of the age distribution of the tagged fish.

For any of the growth models above, individual variation in feeding rates (but not metabolic rates), i.e. in $\mathrm{L}_{\infty}$, can be represented as a multiplicative departure $R_{i}$ of individual i's size at age from the population mean size, i.e. $\mathrm{L}_{\mathrm{i} 1}=\bar{L}\left(a_{1 i}\right) \mathrm{R}_{\mathrm{i}}$,

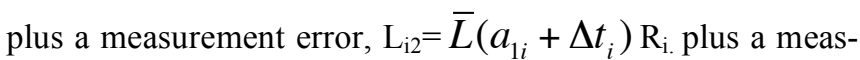
urement error. Here $a_{1 i}$ is the age of fish $i$ at tagging (an integer year plus deviation of capture date from date when $\mathrm{a}=0$. $\bar{L}(a)$ is the population mean growth function, dependent on length at first modeled age 0 and on all the parameters $(\mathrm{H}, \mathrm{m}$, Q10's, etc.) used to predict mean length over time and age. Assuming normally distributed, independent measurement errors with variance $\sigma_{m}^{2}$ and normally distributed sample $R_{i}$ with mean 1.0 and variance $\sigma_{R}^{2}$, it is easily seen that the maximum likelihood estimate of $\mathrm{R}_{\mathrm{i}}$ given any assumed age $\mathrm{a}_{1 \mathrm{i}}$ is given by

$$
\begin{aligned}
& \hat{\mathrm{R}}_{i}\left(a_{1 i}\right)=\left[\bar{L}\left(a_{1 i}\right) \mathrm{L}_{\mathrm{i} 1}+\bar{L}\left(a_{1 i}+\Delta t_{i}\right) \mathrm{L}_{\mathrm{i} 2}+\sigma_{m}^{2} / \sigma_{\mathrm{R}}^{2}\right] / \\
& {\left[\bar{L}\left(a_{1 i}\right)^{2}+\bar{L}\left(a_{1 i}+\Delta t_{i}\right)^{2}+\sigma_{m}^{2} / \sigma_{\mathrm{R}}^{2}\right]}
\end{aligned}
$$

This estimate of $\mathrm{R}$ is just the weighted average of the two $\mathrm{L} / \bar{L}$ observations, but corrected toward 1.0 in cases where $\sigma_{R}^{2}$ is assumed small compared to the measurement variance. The log-likelihood of each $\mathrm{L}_{\mathrm{i} 1}, \mathrm{~L}_{\mathrm{i} 2}$ observation $\mathrm{i}$ given this maximum likelihood estimate of $R_{i}$ is then proportional to (ignoring constant terms shared by all observations)

$$
\begin{gathered}
\ln L_{\mathrm{i}}\left(\mathrm{a}_{1 \mathrm{i}}\right)=-\left[\left(\hat{\mathrm{R}}_{i}\left(a_{1 i}\right) \bar{L}\left(a_{1 i}\right)-\mathrm{L}_{\mathrm{i} 1}\right)^{2}+\left(\hat{\mathrm{R}}_{i}\left(a_{1 i}\right)\right.\right. \\
\left.\left.\bar{L}\left(a_{1 i}+\Delta t_{i}\right)-\mathrm{L}_{\mathrm{i} 2}\right)^{2}\right] / \sigma_{\mathrm{m}}^{2}-\left(\hat{\mathrm{R}}_{i}\left(a_{1 i}\right)-1.0\right)^{2} / \sigma_{\mathrm{R}}^{2}
\end{gathered}
$$

This likelihood term for each fish also represents the Jacoby approximation to the total likelihood of the $\mathrm{L}_{\mathrm{i} 1}, \mathrm{~L}_{\mathrm{i} 2}$ observations, integrated over possible "process errors" $\mathrm{R}_{\mathrm{i}}$.

Eq. (21) can be used in two ways. First, the discrete $a_{1 i}$ that maximizes eq. (21) is the maximum likelihood estimate of the age of fish $i$ at tagging. Second, summing such maxi- 
mum likelihoods over fish i represents a likelihood function for the data, comparable to eq. (10):

$$
\ln L=\sum_{i} \max _{a 1 i_{i}}\left[\ln L_{i}\left(a_{1 i}\right)\right]
$$

In simulation tests with fake data generated for fish with discrete ages, using this likelihood function for estimation of bioenergetics parameters results slightly more precise parameter estimates than eq. (10), with no apparent bias. (the dependence of it on parameters H, m, Q10's etc. is via the predicted mean lengths ). Though eq. (22) is not strictly a smooth function of the parameters, it does not appear to cause nonlinear search procedures like Excel's Solver to "hang" near parameter combinations for which there are discrete changes in the function.

Estimation performance with eq. (22) should be improved considerably by including auxiliary information on lengths at age for a sample of fish aged by modal progression or counts of annuli on hard parts. Suppose such a sample of $j=1 \ldots n$ fish of lengths $L_{j}$ at ages $a_{j}$ is available. To include such independent size-at-age data in the log likelihood function (either eq. 22 or the simpler eq. 10) while assuming normally distributed deviations around mean lengths at age, simply add the following term to $\ln \mathrm{L}$ :

$$
-\sum_{\mathrm{j}=1}^{\mathrm{n}}\left[\left(\mathrm{L}_{\mathrm{j}}-\overline{\mathrm{L}}\left(\mathrm{a}_{\mathrm{j}}\right)\right)^{2} /\left(\sigma_{\mathrm{D}} \overline{\mathrm{L}}\left(\mathrm{a}_{\mathrm{j}}\right)\right)^{2}+\ln \left(\sigma_{\mathrm{D}} \overline{\mathrm{L}}\left(\mathrm{a}_{\mathrm{j}}\right)\right)\right]
$$

This term is simply the normal log-likelihood omitting additive terms that are constants or depend only on the data.

It is not a trivial task to maximize the likelihood function (sum of eq. 22 and 23), since this function can have discrete jumps associated with the discrete individual age parameters and also with discrete time solution of the predicted mean lengths at age. However, the maximum of the function can be found by using Markov Chain Monte Carlo (MCMC) sampling, treated as a random search method, while simultaneously mapping the function so as to provide assessments of uncertainty for the parameter estimates. We recommend using a two-step estimation procedure: (1) first use Solver in an Excel implementation of the model to search for parameter estimates that roughly fit the data, then (2) use MCMC sampling starting from these initial parameter estimates to map the likelihood function. An example spreadsheet to do (1) and a Visual basic application to do (2) are freely available from the senior author; the spreadsheet and visual basic files include the complete data used by Taylor and Walters (this supplement) for the pygmy pikeminnow case study.

As an example of using the likelihood eq. (22)-(23) for estimation and age reconstruction, we examined a tagging and otolith age data set currently being collected for pygmy pikeminnow from lakes of the Bonaparte Plateau, British Columbia [26]. This data set contains both over-summer and fall to early summer (with some period of fall and spring growth) tag recoveries (2032 fish), and a large sample of fish aged by otoliths (2621 fish) of which a small subset (181 fish) were also tag recoveries thereby allowing comparison of otolith age to the estimated age determined by maximiz- ing eq. (21) over age. The sampled lakes are all cold, with maximum summer temperatures rarely exceeding $20^{\circ} \mathrm{C}$ and with a very short growing season (2-4 months) when temperatures are above $4 \mathrm{C}^{\circ}$. Fits of the general bioenergetics model with temperature effects (eqs. 13-15) resulted in predicted body lengths declining during winter, with high estimates for $\mathrm{Q} 10$ parameters $\left(\mathrm{Q}_{\mathrm{c}}, \mathrm{Q}_{\mathrm{m}}\right)$ implying that growth virtually ceases at temperatures below $6-8 C^{\circ}$. Similar estimates were obtained when we fit the data using eqs. 14-15, 16 , and 18-19, which constrain length growth rate to be zero or positive (Fig. 3, Fig. 5). The $\mathrm{Q}_{\mathrm{m}}$ (metabolism) estimates ranged from 2-10 depending on assumed ratios $\sigma_{m}^{2} / \sigma_{R}^{2}$, varying around the value of 2.97 obtained in laboratory studies (Cech et al. 1994) [32], and the predicted decline in effective body weight during winter is in good agreement with predictions from bioenergetics models for this species [27] and with winter tagging studies in Cultus Lake by Steigenberger (1972) [28]. Estimated $\mathrm{Q}_{\mathrm{c}}$ (6.0-12.0 depending on $\mathrm{Q}_{\mathrm{m}}$ estimate) imply a roughly 10 -fold increase in feeding rate as temperature increases from 10 to $20^{\circ} \mathrm{C}$; this surprisingly abrupt increase agrees well with laboratory estimates of temperature effects on digestion rate for Cultus Lake, B.C. pikeminnow [29] (Bonaparte plateau and Cultus Lakes are in the same, Fraser River watershed). Only the net scope for growth is "visible" in growth data, and the fitting procedure traded off $\mathrm{H}, \mathrm{m}, \mathrm{Q}_{\mathrm{m}}$, and $\mathrm{Q}_{\mathrm{c}}$ so as to give nearly the same pattern of variation in growth rate with temperature (Fig. 5) while varying $Q_{m}$ widely (that is, the data do not provide enough information to estimate all four parameters independently). This instability in the Q10 parameter estimates was not alleviated by simultaneously fitting both the tagging data and the otolith size-age data.

As expected from applying the age estimation procedure to simulated data with substantial measurement error and individual variation in growth rates, the pikeminnow age estimates from tagging vary widely around those obtained from otoliths for the small sample of tagged pikeminnow that were actually aged at recapture (Fig. 7). Interestingly, the estimated individual growth deviations $R_{i}$ warn that there was size-selective sampling (bias toward including faster growing individuals in the sample) as found by Taylor et al. (2004). Despite the imprecision in aging, catch curves constructed from the otolith age data and from ages of all recaptured fish (Fig. 6) result in very similar estimates of total mortality rate $(Z=0.24$ from tag data, 0.27 from tagging for ages 5-19, and 0.27 for both data sets using ages 6-19). Further, the age reconstruction from tagging clearly shows how tagging was restricted to older, larger fish that were thought capable of carrying spaghetti tags without severe adverse behavioral effects.

The pikeminnow case can also be used to examine a question commonly asked of bioenergetics models, namely whether the parameter estimates can be used to predict changes in growth under altered physical conditions, particularly changes in temperature patterns (as might happen for example under global warming). Taking the Bonaparte plateau parameter estimates, we replaced the seasonal temperature pattern with known patterns for two warmer lakes where pikeminnow growth patterns have been measured, John Day Reservoir on the Columbia and Cultus Lake in the lower Fraser River watershed. For both of these cases, bioenerget- 


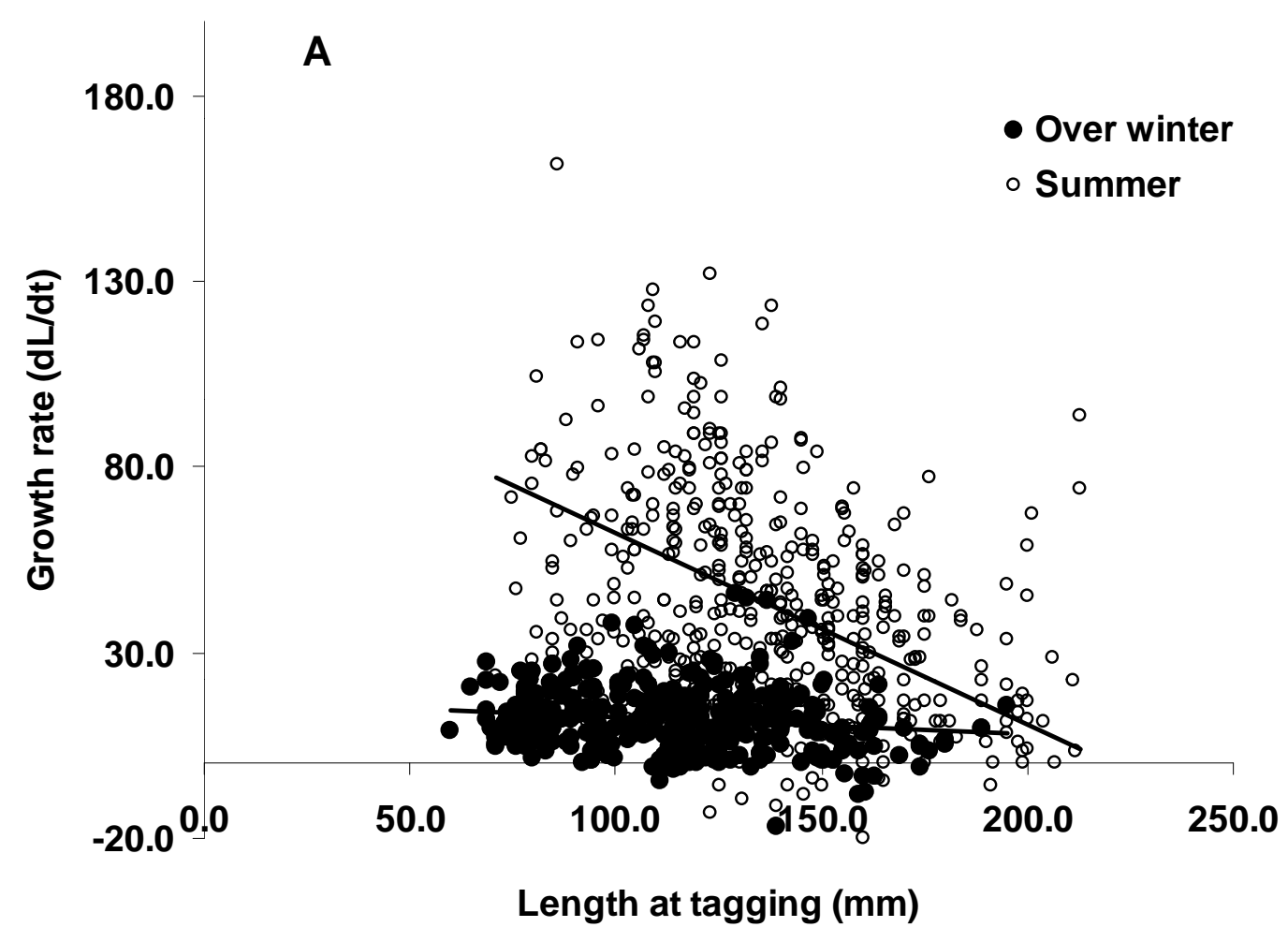

B

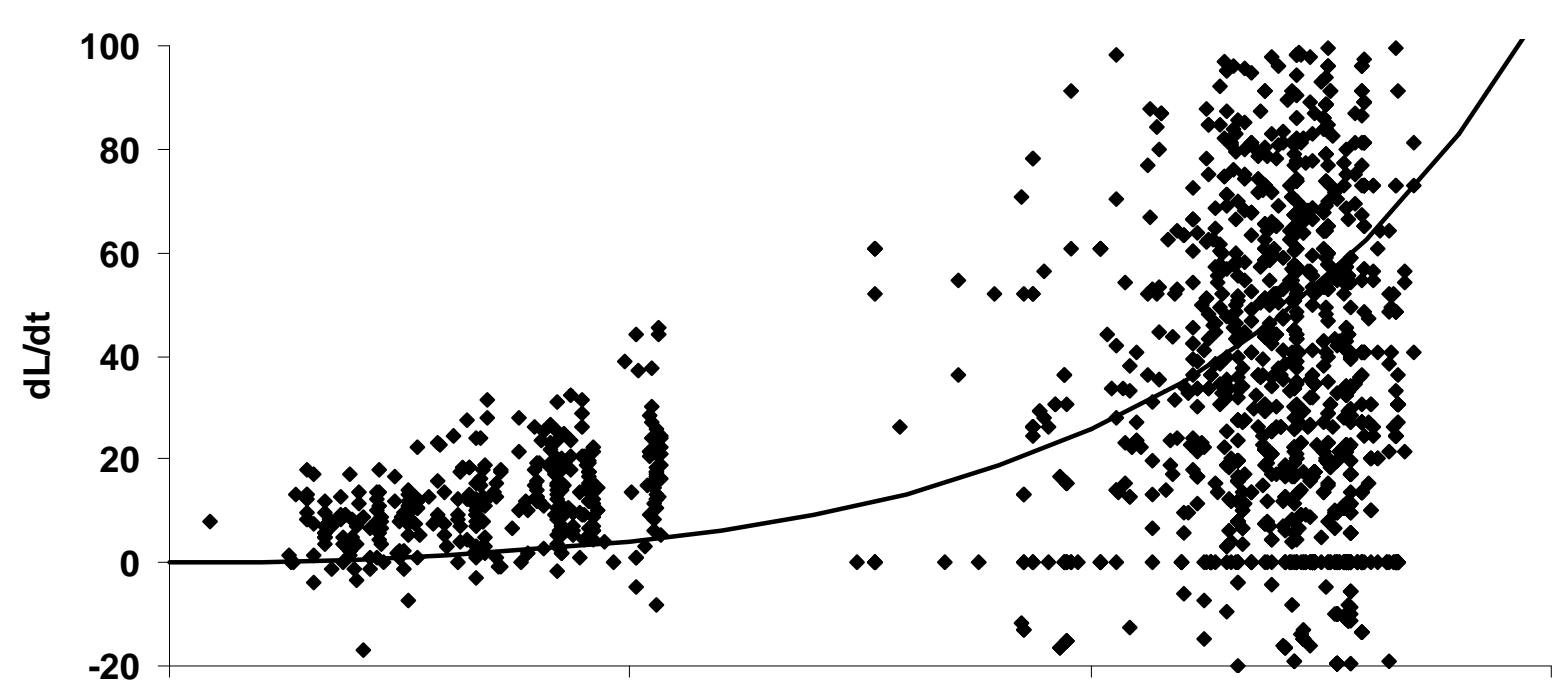

Fig. (5). Diagnostic plots for spaghetti tag returns of pikeminnow from lakes of the Bonaparte Plateau, British Columbia. A- over-summer versus fall-spring growth rates $(\Delta \mathrm{L} / \Delta \mathrm{t}) ; \mathbf{B}$ - Scope for growth (growth rate under constant temperature, solid line) compared to measured growth rates for individuals in relation to mean temperature over the period from tagging to recapture; note that individuals showing positive growth at low mean temperature are estimated to have achieved that growth during fall and spring periods when temperature was well above the average over the period from tagging to recapture. $\mathrm{C}$ - maximum likelihood estimates of relative growth rate $\left(\mathrm{R}_{\mathrm{i}}\right)$ for individuals included in the tag recapture sample; note bias toward inclusion of faster-growing, larger individuals at younger ages. 

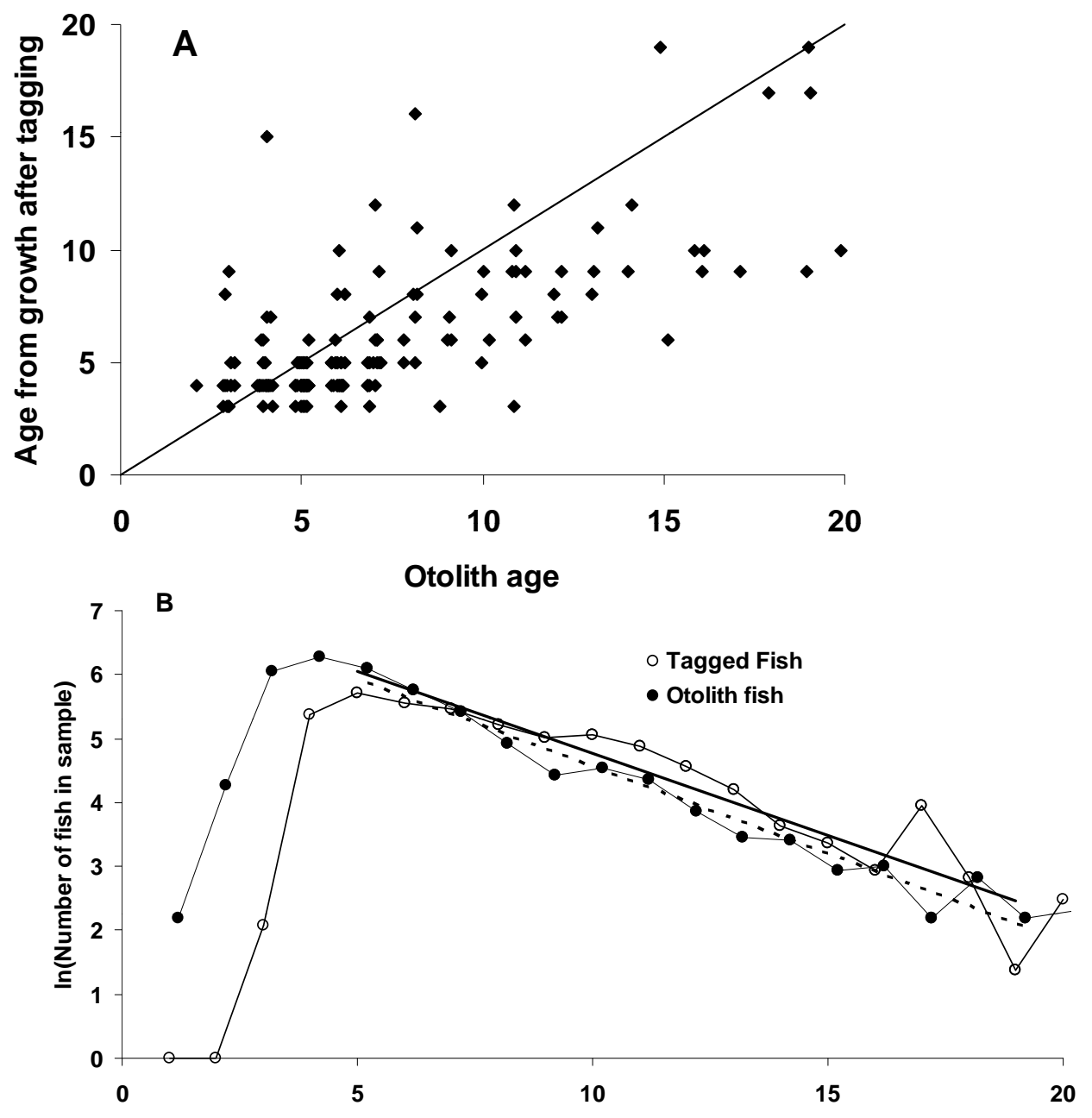

Fig. (6). Comparison of ages and mortality rates estimated from otoliths to ages and rates calculated from tag-recapture sizes, for pikeminnow from the Bonaparte Plateau, British Columbia. A-maximum likelihood age estimate versus otolith age estimate for a sample of individuals that were aged upon recapture ( $\mathrm{n}=181 \mathrm{fish}$ ). B-Catch curves (log number of fish at age) constructed from otolith ages ( $\mathrm{n}=2621$ ) versus ages estimated from mark-recapture sample $(n=2032)$.

ics studies and fits to vonBertalanffy growth curves indicate similar catabolic $(\mathrm{K})$ parameters to what we estimated for the Bonaparte populations. But for both, the Bonaparte fitted model substantially underpredicts growth rate and maximum body length for older fish (Fig. 7). Very likely the problem here is with the anabolic (feeding rate) parameter $\mathrm{H}$; the Bonaparte fish have only a limited invertebrate food supply, while small fishes (e.g. juvenile salmonids) are abundant and consumed regularly in the two warmer systems. Estimates of the size allometry power parameters $(\mathrm{d}, \mathrm{n})$ support this interpretation. When we allowed $\mathrm{d}, \mathrm{n}$ to vary from default values of 0.67 and 1.0 (specialized vonBertalanffy model), the parameter estimation failed (too many parameters). But when we constrained the metabolic power parameter $\mathrm{n}$ to the upper end of the range of values reported in laboratory studies (0.93) there was a slightly poorer model fit $(\Delta \ln L=$ $2.42, \Delta \mathrm{AIC}=-0.42)$, but the resulting estimate of $\mathrm{d}=0.61 \mathrm{im}$ plies slower increase in feeding rate with body size than would be predicted from laboratory estimates, as expected when fish prey are not available to the larger individuals.
Laboratory studies $[27,30,31]$ would predict $d$ to be much larger, around $0.8(0.72$ to 0.89$)$ and $\mathrm{n}$ to be lower, around $0.72(0.52$ to 0.91$)$.

Our estimated metabolic parameter m $(0.235$, annual metabolic loss per body weight at $10^{\circ} \mathrm{C}$ )) is remarkably close to the Cech et al. (1994) [31] estimate of 0.25 for $800 \mathrm{~g}$ fish. However, their estimate of $\mathrm{n}(0.72)$ extrapolates a much higher metabolic rate per mass $(0.49)$ at $10^{\circ} \mathrm{C}$ for the smaller $(60 \mathrm{~g})$ Bonaparte fish. Forcing the model with the Cech et al. estimates, while estimating only $\mathrm{H}, \mathrm{d}$, and $\mathrm{Q}_{\mathrm{c}}$, results in estimated $\mathrm{d}=0.55, \mathrm{Q}_{\mathrm{c}}=41.8$; these estimates reverse the predictions in Fig. (7), implying much larger asymptotic body sizes in warm environments than observed, and a considerably poorer fit to the data $(\Delta \ln L=-5.97)$.

\section{DISCUSSION}

Our estimates of ontogenetic and seasonal changes in consumption rates for the case examples are in general agreement with expectations from more detailed bioenerget- 


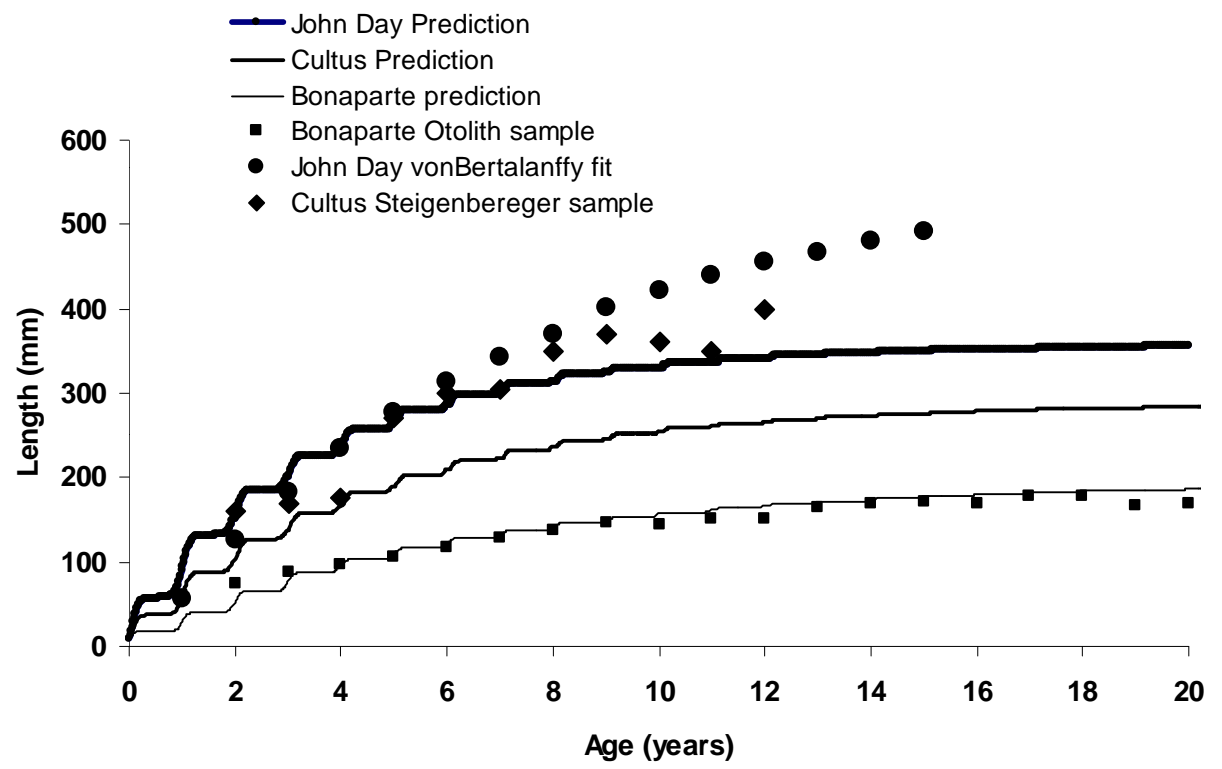

Fig. (7). A test of whether the bioenergetics model for Bonaparte plateau pikeminnow can successfully predict growth patterns in warmer lakes. Bonaparte fitted model was supplied with annual temperature patterns from Cultus Lake and John Day Reservoir, without any changes in the anabolic or catabolic parameters. Note gross underprediction of growth rates for the two warmer lakes. Cultus measured body lengths from Steigenberger (1972) [28]; John Day lengths from Rieman and Beamesderfer (1990) [32].

ics modeling. For the cyprinid species, we estimate very low peak consumption rates by adult fish, on order $0.2-0.4 \%$ per day. We estimate peak consumption rates for adult trout of $1-2 \%$ per day. For all the species, we estimate consumption rates to decline with age so as to reach these low adult rates by about age 3 .

For those who need to use bioenergetics analysis for purposes such as estimation of food consumption rates, but are suspicious about basing such analysis on food consumption and metabolic relationships derived under laboratory conditions or about "borrowing" parameters from other species, it appears from the examples reviewed above that some bioenergetics information can be recovered from field tagging and body size information. In particular it is possible to represent effects related to seasonal changes in rates due to temperature (via $f_{c}$ and $f_{m}$ functions), and to determine the effect of such changes on estimation of summary quantities such as annual food consumption (integral of ration estimates $\mathrm{R}$ over time). It appears possible to use the simple CR model in some cases like Cabin Lake rainbow trout and pikeminnow to estimate Q10 coefficients for temperature dependence of feeding and metabolism from field data alone, a task typically relegated to laboratory studies.

It is less often possible to recover information about patterns of body size allometry, particularly in feeding rates. As shown in the humpback chub case, body size effects are likely to be confounded with effects of seasonal and ontogenetic habitat shifts that alter temperature patterns encountered by animals as they grow. However, the humpback chub example also suggests that growth information may be useful in a reverse way, for estimating when ontogenetic shifts into different thermal regimes are most likely to have occurred. The field mass dependence pattern may also be due to restrictions in food availability for larger individuals (as in the pikeminnow case).
The humpback chub and pikeminnow examples suggest an important challenge for bioenergetics models that predict intake and metabolism from size and temperature only. In these examples, small juveniles appear to actively seek warmer environments (tributary streams, warm shorelines) than larger fish, suggesting that their scope for growth is maximum at lower temperatures. Such size-dependent change in optimum temperature ( $T$ for which $\mathrm{dW} / \mathrm{dt}$ is maximum) is predicted by the models described in this paper even when the same $f_{c}(T)$ function is used for fish of all sizes, except when $Q_{c}>>Q_{m}$ (consumption rate changes much more rapidly with temperature than metabolism rate). Laboratory estimates of $\mathrm{Q} 10 \mathrm{~s}$ for food consumption $\left(\mathrm{Q}_{\mathrm{c}}\right)$ do not account for changes in food availability that are correlated with temperature, and it is entirely possible that effective $Q_{c}$ values are commonly low under field conditions, especially for larger fish simply because larger fish tend to target larger food organisms (e.g. small fish, insects) that have less seasonal variability in abundance than the food organisms targeted by small fish (e.g. zooplankton). Lower $\mathrm{Q}_{\mathrm{c}}$ for generally implies maximum scope for growth at lower temperatures, especially if that lower value applies selectively to larger fish. To model such selective effects, the $f_{c}(T)$ function would need to be replaced by a more complex $f_{c}(W, T)$ function, for which the effects of $\mathrm{W}$ on $\mathrm{Q}_{\mathrm{c}}$ cannot be estimated from laboratory studies if these effects derive from effects at field scale on food availability.

Unfortunately we cannot offer any reliable general guidelines about conditions that field data must satisfy in order for the mass power parameters and/or temperature coefficients to be reliably estimated. Careful Monte Carlo simulation studies of probable estimation performance, and analysis of parameter uncertainty by the usual methods (parameter covariance matrices, MCMC sampling of likelihoods and posteriors) need to be done on a case-by-case basis. We can say that tagging data appear to be better for estimation of bioenergetics parameters than data on size at age, particularly in 


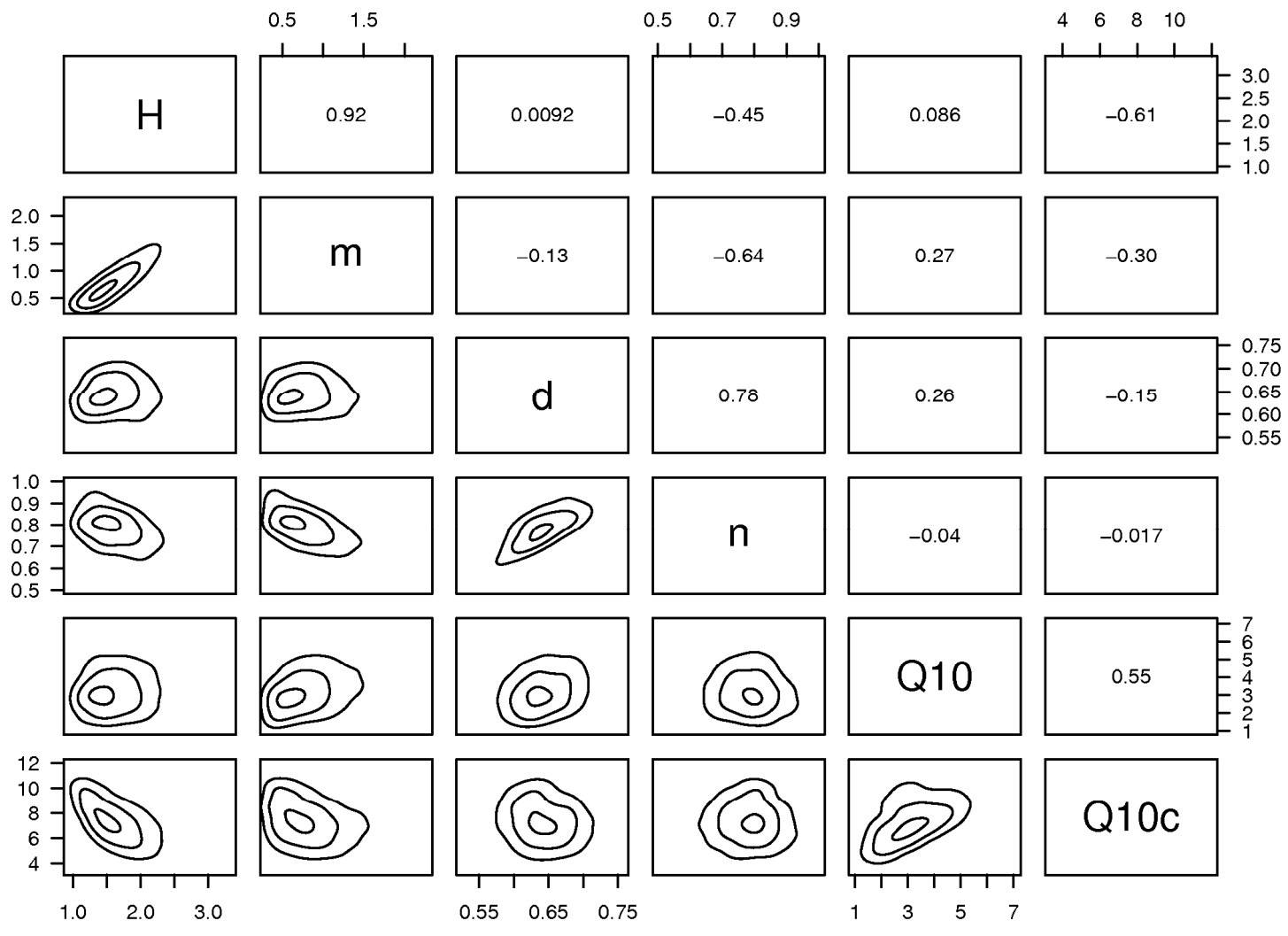

Fig. (8). Pairs plot of MCMC results from 100,000 samples of the likelihood function for the pikeminnow data, complex bioenergetics model and likelihood assumptions. Contours indicate parameter combinations with high likelihood; parameter correlations shown in upper right panels.

cases where many tags are recovered after exposure to just one strongly contrasting seasonal temperature regime (summer or winter). We encourage the use of pairs plots from MCMC sampling to assist in determining which particular parameter estimates are most badly confounded, for example such plots reveal severe confounding of $\mathrm{H}$ and $\mathrm{m}, \mathrm{d}$ and $\mathrm{n}$ in the pikeminnow example (Fig. 8).

We hesitate to recommend using the relatively complex SRSA model that includes allocation to skeletal vs somatic growth (eqs. 16-19) except in cases like the pikeminnow where there are extended seasonal periods of zero length growth or cases like the New Zealand brown trout where there are large seasonal energy losses to reproduction. The overall parameter estimates from this model were not much different from those obtained with simpler models that predicted negative length growth in winter, it was very difficult to manually choose reasonable values for the allocation parameters, and statistical estimation procedures for any model with discontinuous changes (allocation to skeletal tissue cut as growth approaches zero) are prone to difficulties due to discontinuous derivatives of the likelihood function with respect to the parameters. Perhaps such models can be better parameterized for cases where auxiliary information on caloric content or dry weight of fish at recapture has been obtained (wet weights are likely to be misleading due to changes in water content of fish that have lost much somatic mass, eg through reproduction), but we do not have access to test data from any such cases.
While we found the bioenergetics parameter estimates to be relatively unstable, i.e. a wide range of estimates could almost equally well explain observed growth patterns, such uncertainty does not directly imply high uncertainty in estimates of food consumption rate. As noted above, consumption rate estimates are basically a "backcalculation" of the form $\mathrm{R}=\left(\mathrm{dW} / \mathrm{dt}+\mathrm{mW}^{\mathrm{n}}\right) / \mathrm{e}$. So if the model fitting procedure is successful at finding parameter values that fit the observed $\mathrm{dW} / \mathrm{dt}$ pattern, and if the $\mathrm{m}, \mathrm{n}$ parameters for standard metabolism are reasonably estimated, then ration $\mathrm{R}$ will be reasonably well estimated up to uncertainty about assimilation efficiency and SDA (the e parameter). Since only the product $\mathrm{eR}$ is visible in field growth data, there is no way to use such data to estimate e separately from the $\mathrm{H}, \mathrm{d}, \mathrm{Q}_{\mathrm{c}}$ parameters used to predict $\mathrm{eR}$.

To further evaluate the possibility that estimated ration patterns are relatively insensitive to problems in estimation of some model parameters, we fitted the more complex SRSA model (eqs. 12-19) using the likelihood function that assumes seasonal reproduction (eq. 22) to six data sets for which the model is being used by colleagues (Table 3 ). We first constrained two metabolic parameters to reasonable values based on laboratory studies $\left(\mathrm{Q}_{\mathrm{m}}=2.0, \mathrm{n}=0.8\right)$, which resulted in reasonable estimates for $\mathrm{H}, \mathrm{m}, \mathrm{d}$, and $\mathrm{Q}_{\mathrm{c}}$. Then we freed $Q_{m}$ and $n$ to vary in the nonlinear estimation procedure, which resulted in unrealistic values for at least some parameters for most cases (e.g. $Q_{m}<1.0$ ). Despite the unrealistic parameter values from the larger parameter search, calculated 
(a)

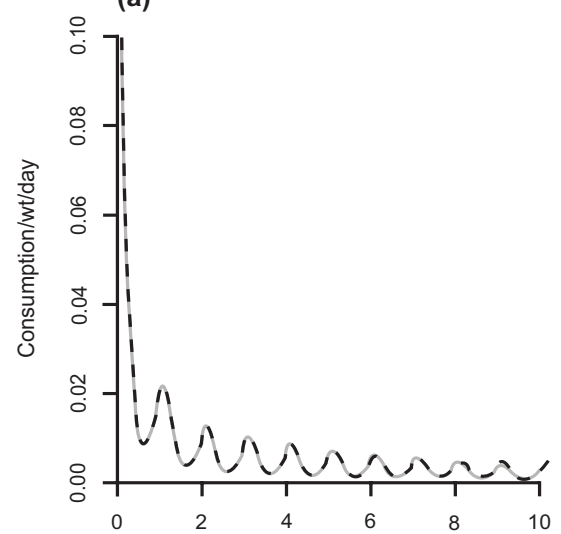

(b)

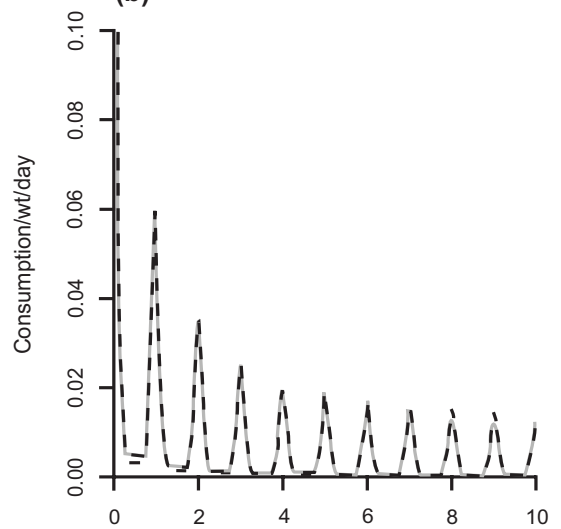

(c)

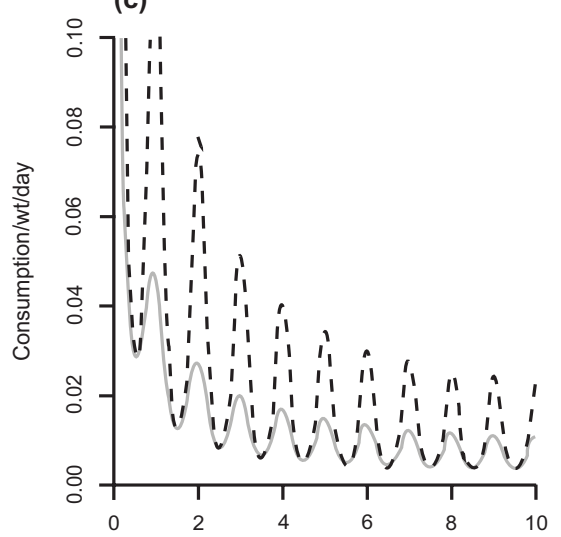

(d)

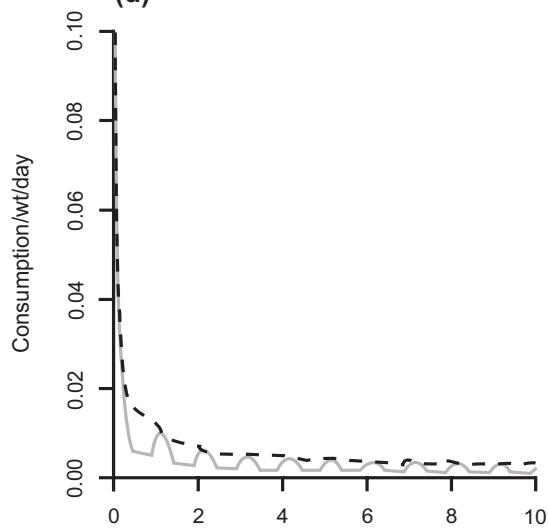

(e)

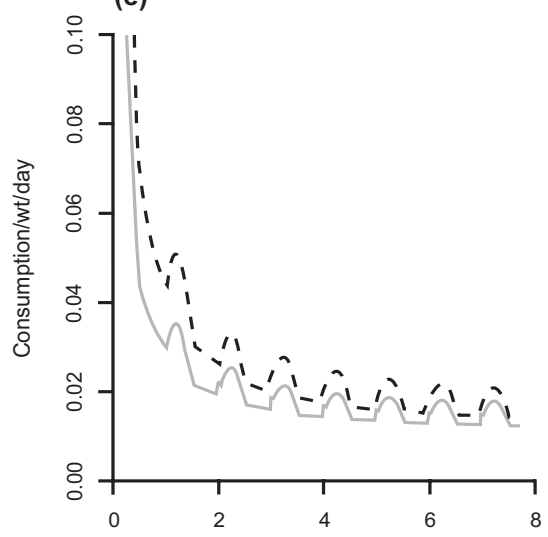

(f)

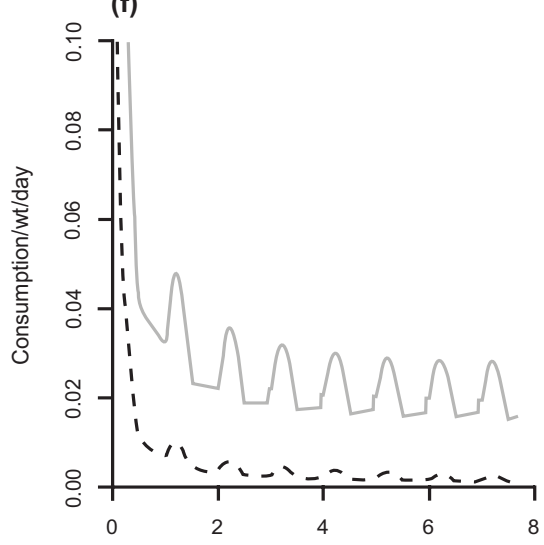

Fig. (9). Comparison of predicted lifetime food consumption rates for various species used to test model fitting procedures, using parameter estimates for these species (Table 3) obtained with and without constraining $Q_{m}$ and $n$ parameters. (a) humpback chub, (b) pikeminnow, (c) flathead catfish, (d) rainbow trout, (e) Chassowiska River largemouth bass, (f) Homossassa River largemouth bass. Estimates with $\mathrm{Q}_{\mathrm{m}}$, $\mathrm{n}$ constraint shown in gray.

ration vs age relationships were very similar to (within $10 \%$ of) those from the constrained search and from fitting simpler models, for the large-sample cases (humpback chub and pikeminnow). But for the four small sample cases, predicted life-time total food consumptions were as low as $50 \%$ and as high as $250 \%$ of those predicted by the constrained model and by the simpler bioenergetics model without seasonal reproduction and skeletal dynamics (Fig. 9).

A disappointment in this study was that we were unable to test predictions of the SRSA model about seasonal changes in condition factor $(\mathrm{CF})$ and to develop good estimates of the skeletal allocation parameters $\theta$ and $W_{\infty}$. By varying $\mathrm{W}_{\infty}$, we were able to reproduce observed differences among the case species in progressive change of CF with age. The catfish and largemouth bass data sets show substantial increase in $\mathrm{CF}$, to mean values around 1.2 for older fish, whereas the brown and rainbow trout data show declining CF after maturity. No clear pattern with age was evident for humpback chub and pikeminnow. But we could see no clear seasonal pattern in CF for any of the species, and in particular we could not see the sharp drop and rapid recovery in $\mathrm{CF}$ 
predicted to be associated with spawning. Two factors evidently masked the sharp drop that individual fish are likely to have shown: rapid replacement of mass lost to gonadal products by water content (which would only be visible in measurements of energetic content rather than total body weight), and asynchrony among individuals in spawn timing so that each field sample near the mean spawning time consisted of a mixture of individuals in different stages of spawning and recovery.

The case studies lead to some specific recommendations for researchers who might wish to apply the models and estimation methods described in this paper. First, always use both size-at-age and tagging data for parameter estimation, particulary in cases where one or another of these data sources may have selection biases like tendency to sample or mark faster growing fish. Second, include data on size-at-age for very small (age 0) juveniles whenever possible, for example from seasonal length-frequency sampling, in order to provide data on growth for the widest possible range of fish sizes (and hence better estimates for the troublesome size allometry parameters). Third, in design of tagging studies, seek to tag and recapture fish over as many months of the year as possible, particularly the fall-winter period, so as to provide estimates of growth rate over the widest possible range of temperatures. Fourth, if practical obtain frequent (e.g. weekly) size-age and growth rate samples during periods of rapid increase in temperature and spawning. These suggestions will not eliminate all parameter confounding, but will minimize the effects on estimation performance of $\mathrm{H}-\mathrm{m}$ and $\mathrm{d}-\mathrm{n}$ confounding.

Bioenergetics models are commonly validated by comparing model estimates to known consumption rates from laboratory experiments. This type of experiment may prove a useful test for the accuracy and precision of consumption rate estimates derived from tagging and size-at-age data. It is possible that both methods will demonstrate the ability accurately predict known consumption rates in laboratory settings, while producing divergent estimates in field settings, thereby highlighting the need for continued improvements and assessments for field-based estimation.

\section{REFERENCES}

[1] Hayes JW, Stark JD, Shearer KA. Development and test of a whole-lifetime foraging and bioenergetics growth model for driftfeeding brown trout. Trans Am Fish Soc 2000; 129: 315-32.

[2] Chipps SR, Wahl DH. Bioenergetics modeling in the 21st centure: Reviewing new insights and revisiting old constraints. Trans Am Fish Soc 2008; 137: 298-313.

[3] Pauly D. The relationship between gill surface area and growth performance in fish: a generalization of von Bertalanffy's theory of growth. Meeresforschung 1980; 28: 251-82.

[4] Temming A. Food conversion efficiency and the von Bertalanffy growth function. Part II and conclusion: extension of the new model to the generalized von Bertalanffy growth function. NAGA: the ICLARM Quarterly 1994; vol. 17: pp. 41-5.

[5] Essington TE, Kitchell JF, Walters CJ. The von Bertalanffy growth function, bioenergetics, and the consumption rates of fish. Can $\mathrm{J}$ Fish Aquat Sci 2001; 58: 2129-38.

[6] Paloheimo JE, Dickie LM. Food and growth of fishes.1. A growth curve derived from experimental data. J Fish Res Board Can 1965; 22: 521 .

[7] Hewitt SW, Johnson BL. Fish bioenergetics model 2. Madison, WI: University of Wisconsin Sea Grant Institute 1992.

[8] Jobling M. Fish bioenergetics. London: Chapman and Hall 1994.
[9] Gurney WSC, Tyldesley G, Wood SN, et al. Modelling length-atage variability under irreversible growth. Can J Fish Aquat Sci 2007; 64: 638-53.

[10] Clarke A, Johnston NM. Scaling of metabolic rate with body mass and temperature in teleost fish. J Anim Ecol 1999; 68: 893-905.

[11] James IR. Estimation of vonbertalanffy growth curve parameters from recapture data. Biometrics 1991; 47: 1519-30.

[12] Francis R. Maximum-Likelihood estimation of growth and growth variability from tagging data. NZ J Mar Freshw Res 1988; 22: 4351.

[13] Laslett GM, Eveson JP, Polacheck T. A flexible maximum likelihood approach for fitting growth curves to tag-recapture data. Can J Fish Aquat Sci 2002; 59: 976-86.

[14] Sainsbury KJ. Effect of individual variability on the von bertalanffy growth equation. Can J Fish Aquat Sci 1980; 37: 241-7.

[15] Clarke A, Johnston NM. Scaling of metabolic rate with body mass and temperature in teleost fish. J Anim Ecol 1999; 68: 893-905.

[16] Coggins LG, Pine WE, Walters CJ, Van Haverbeke DR, Ward D, Johnstone HC. Abundance trends and status of the little Colorado River population of humpback chub. N Am J Fish Manag 2006; 26: 233-45.

[17] Robinson AT, Childs MR. Juvenile growth of native fishes in the Little Colorado River and in a thermally modified portion of the Colorado River. N Am J Fish Manage 2001; 21: 809-15.

[18] Broekhuizen N, Gurney WSC, Jones A, Bryant AD. Modeling compensatory growth. Funct Ecol 1994; 8: 770-82.

[19] Jones W, Gurney WSC, Speirs DC, Bacon PJ, Youngson AF. Seasonal patterns of growth, expenditure and assimilation in juvenile Atlantic salmon. J Anim Ecol 2002; 71: 916-24.

[20] Nerini M. In: Jones ML, Swartz SL, Leatherwood S, Eds. A review of gray whale feeding ecology. (THE GREY WHALE Eschrichtius robustus. London, UK: Academic Press 1984, pp. 423-50.

[21] Charnov EL, Gillooly JF. Size and temperature in the evolution of fish life histories. Integr Comp Biol 2004; 44: 494-7.

[22] Jørgensen C, Fiksen Ø. State-dependent energy allocation in cod (Gadus morhua). Can J Fish Aquat Sci 2006; 63: 186-99.

[23] Froese R. Cube law, condition factor and weight-length relationships: history, meta-analysis and recommendations. J Appl Ichthyol 2006; 22: 241-53.

[24] Elliott JM. Energetics of feeding, metabolism and growth of brown trout(salmo-trutta-1) in relation to body-weight, water temperature and ration size. J Anim Ecol 1976; 45: 923-48.

[25] Wang YG, Thomas MR, Somers IF. A maximum-likelihood approach for estimating growth from tag-recapture data. Can J Fish Aquat Sci 1995; 52: 252-9.

[26] Wang YG. An improved Fabens method for estimation of growth parameters in the vonBertalanffy model with individual asymptotes. Can J Fish Aquat Sci 1998; 55: 397-400.

[27] Taylor NG, Walters CJ, Martell SJD. A new likelihood for simultaneously estimating von Bertalanffy growth parameters, gear selectivity, and natural and fishing mortality. Can J Fish Aquat Sci 2005; 62: 215-23.

[28] Petersen JH, Ward DL. Development and corroboration of a bioenergetics model for northern pikeminnow feeding on juvenile salmonids in the Columbia River. Trans Am Fish Soc 1999; 128: 784-801.

[29] Steigenberger LW. Observations on the predation by squawfish on sockeye salmon, with particular reference to Cultus Lake [Msc Thesis]. Vancouver, B.C.: University of British Columbia 1972.

[30] Steigenberger LW, Larkin PA. Feeding activity and rates of digestion of northern squawfish (Ptychocheilus-Oregonensis). J Fish Res Board Can 1974; 31: 411-20.

[31] Vigg S, Burley CC. Temperature-dependent maximum daily consumption of juvenile salmonids by northern squawfish (Ptychocheilus-Oregonensis) From The Columbia River. Can J Fish Aquat Sci 1991; 48: 2491-8.

[32] Cech JJ, Castleberry DT, Hopkins TE, Petersen JH. Northern squawfish, ptychocheilus-oregonensis, O-2 consumption rate and respiration model - effects of temperature and body-size. Can J Fish Aquat Sci 1994; 51: 8-12.

[33] Rieman BE, Beamesderfer RC. Dynamics of a northern squawfish population and the potential to reduce predation on juvenile salmonids in a Columbia River reservoir. N Am J Fish Manag 1990; 10: $228-41$. 
[34] Tetzlaff J. Activity, foraging behavior and energetics of largemouth bass (Micropterus salmoides) in two spring-fed coastal rivers [Msc Thesis]. Gainesville, FL: University of Florida 2008.
[35] Pine WE. Population ecology of introduced flathead catfish Ph.D. Dissertation. Raleigh N.C.: North Carolina State University 2003.

Received: November 06, 2008

(C) Walters and Essington; Licensee Bentham Open.

This is an open access article licensed under the terms of the Creative Commons Attribution Non-Commercial License (http://creativecommons.org/licenses/by-nc/3.0/) which permits unrestricted, non-commercial use, distribution and reproduction in any medium, provided the work is properly cited. 